يايش سلامت سازههاى دريايى به روش انرزى كرنشى مودال اصلاح شده (مطالعه

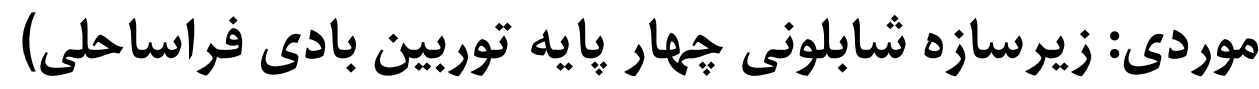

سيد رضا سمائى '، مجيد قدسى حسن آبادّ"، محمد اسديان قهفرخى '، محمد جواد كتابدارى

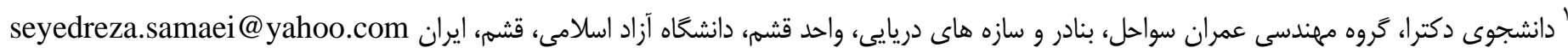

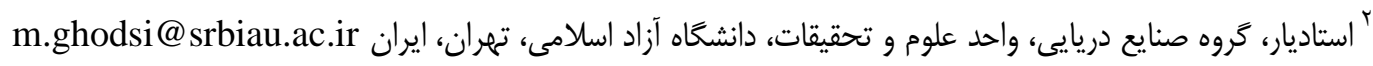

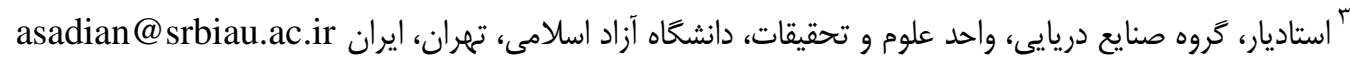

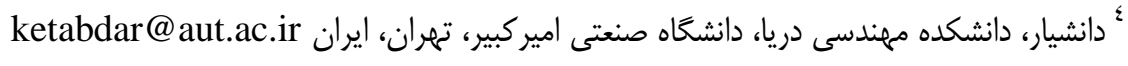

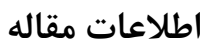

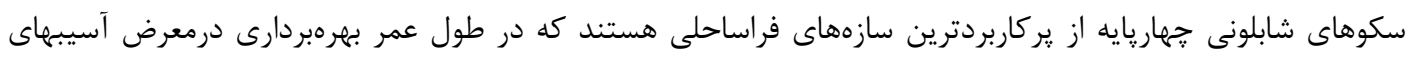
تاريخجه مقاله:

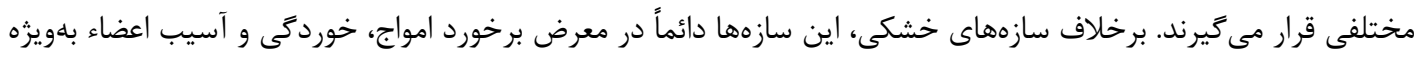

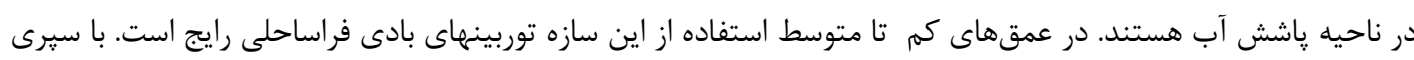

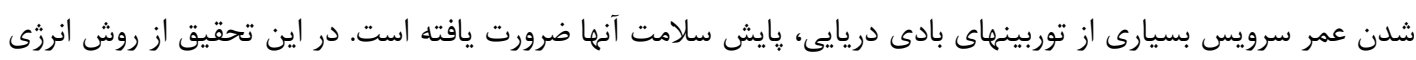

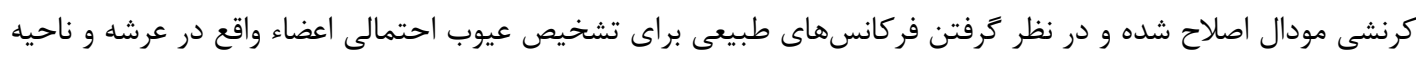

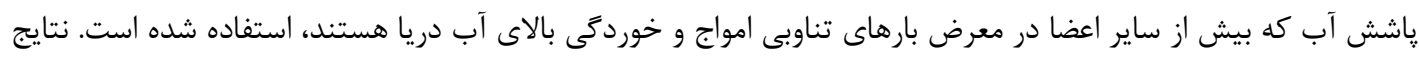

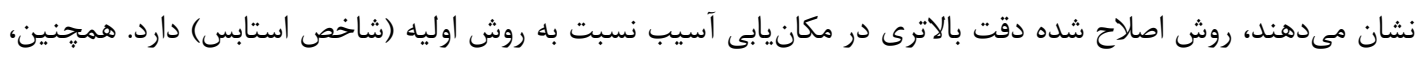

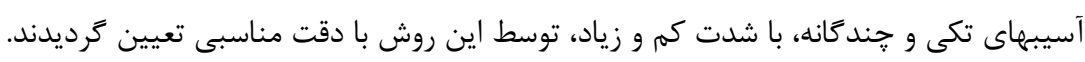

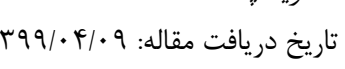

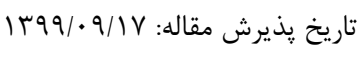

كلمات كليدى: توربين بادى فراساحلى شناسايى آسيب انرخى كرنشى مودال اصلاح شده شاخص استابس

\title{
Structural health monitoring of offshore structures using a modified modal strain energy method (Case study: four-leg jacket substructure of an offshore wind turbine)
}

\section{Seyyed Reza Samaei ${ }^{1}$, Madjid Ghodsi Hassanabad ${ }^{2 *}$, Mohammad Asadian Ghahfarrokhi ${ }^{3}$, Mohammad Javad Ketabdari ${ }^{4}$}

${ }^{1}$ PhD student, Department of Civil engineering-Coasts, ports and Marine structures, Qeshm branch, Islamic Azad university, Qeshm,Iran ; seyedreza.samaei@yahoo.com

2* Assistant professor, Department of Marine industries, Science and Research Branch, Islamic Azad University, Tehran, Iran; m.ghodsi@srbiau.ac.ir

${ }^{3}$ Assistant professor, Department of Marine industries, Science and Research Branch, Islamic Azad University, Tehran, Iran; asadian@srbiau.ac.ir

4 Associate Professor, Department of Marine Technology, Amirkabir University of Technology, Tehran, Iran; ketabdar@aut.ac.ir

\section{ARTICLE INFO}

Article History:

Received: 29 Jun. 2020

Accepted: 07 Dec. 2020

\section{Keywords:}

Offshore wind turbine

Damage detection

Modified modal strain

energy method

Stubbs index

\begin{abstract}
Four-leg jacket is one of the most widely used offshore structures that is exposed to various damages during its service life. Unlike land structures, offshore structures are always exposed to waves, corrosion and damages, especially in the splash zone. At shallow to intermediate water depths, these structures are commonly used as the substructure of offshore wind turbines. Passing their service life has made the structural health monitoring of offshore wind turbines necessary. In this research, a modified modal strain energy method is used for damage detection in deck and splash zone members which are more exposed to periodic loads of waves and high corrosive seawater than other members. The results showed the higher accuracy of the improved modal strain energy method compared to the original method (Stubbs index). Also, using improved method resulted in prediction of single and multiple damages, with low and high intensities with appropriate accuracy.
\end{abstract}




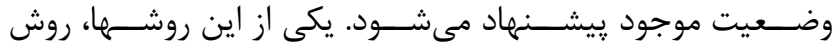

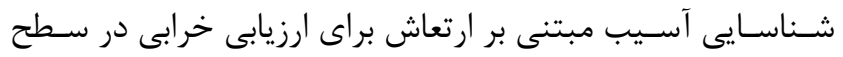

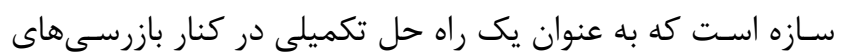

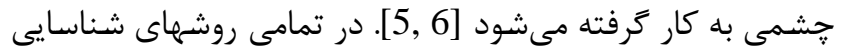
آسيب مبتنى بر ارتعاش، خصوصيات مودال سازه (فر كانس، شكل

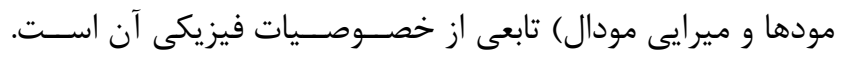
بنابراين مىتوان با استفاده از تغيير در ياسخ استاتيكى يا ديناميكى آنى

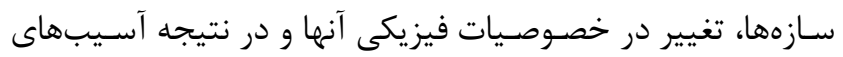

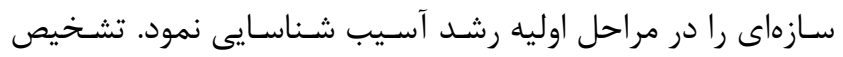

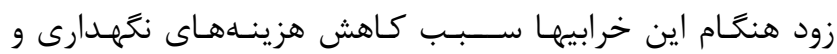
جلوكيرى از شكست سازه مى خردد.

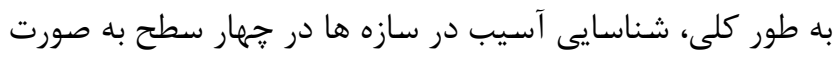
زير طبقه بندى مىشوند:

سطح اول: تشخيص وجود و يا عدم وجود خرابى در سازهها

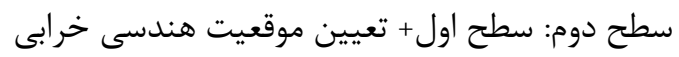

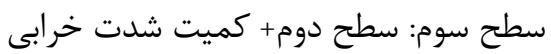
سطح קهارم: سطح سوم+ تخمين عمر باقى مانده [7].

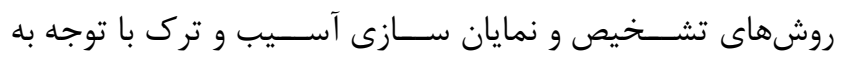

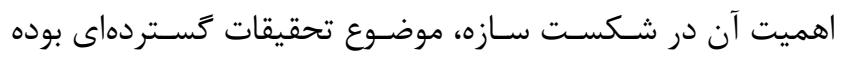

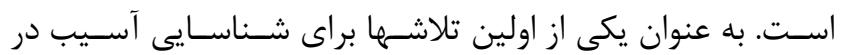

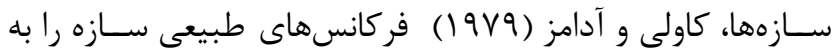

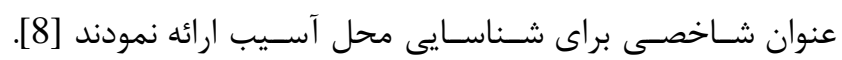

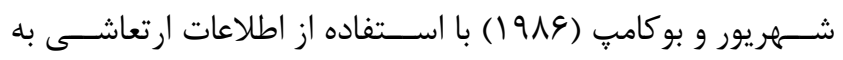

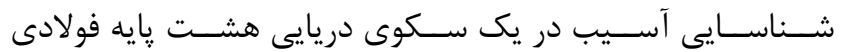

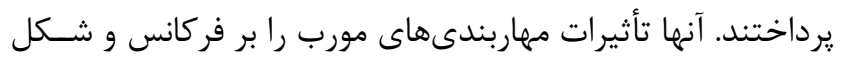

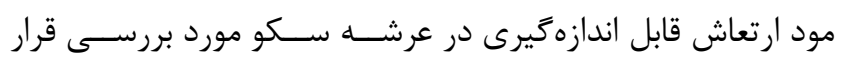

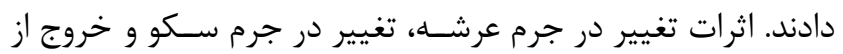

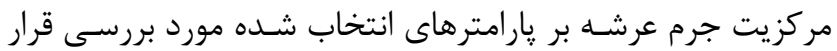

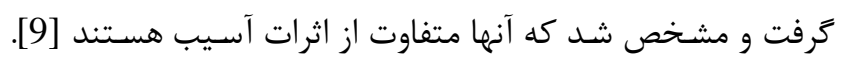

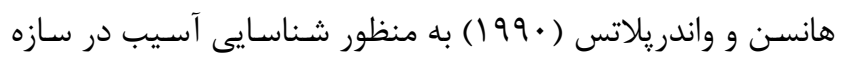

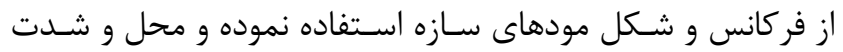

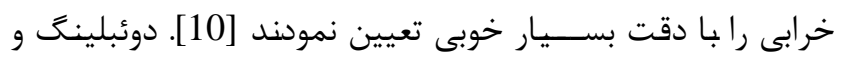

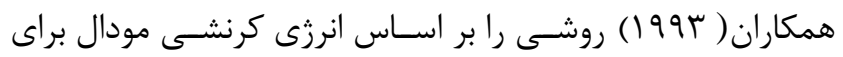

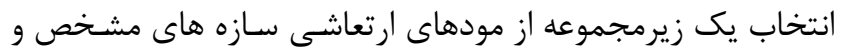

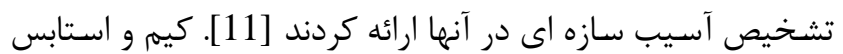

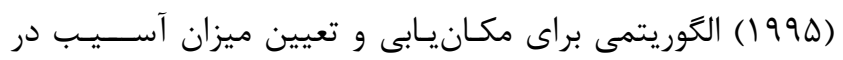

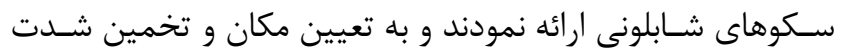

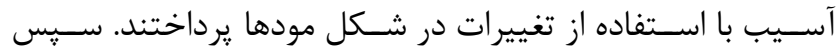

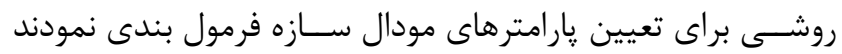

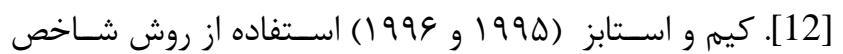
خرابى مبتنى بر انرزى كرنشسى مودال را براى سـازههاى تير مانند

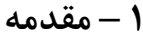

در طول عمر بهرهبردارى در محيط خشن دريايى، سازههاى دريايى

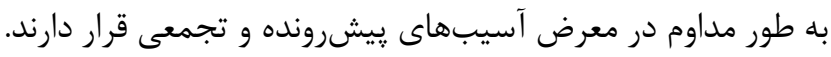

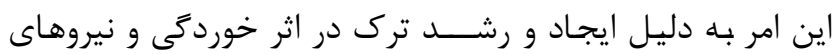

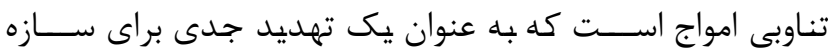

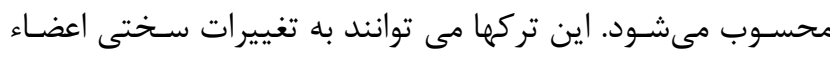

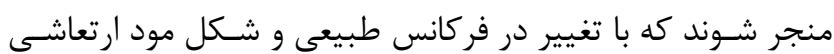

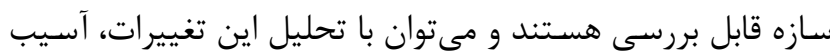
رادر سازه شناسايى نمود.

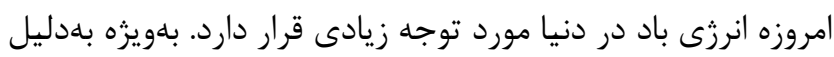

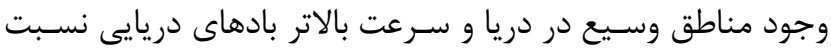

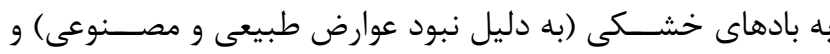

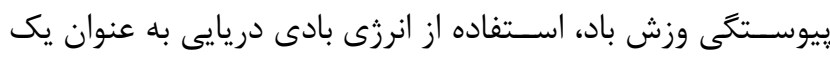

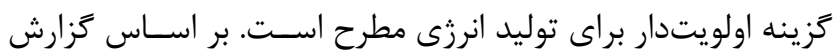

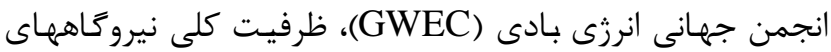

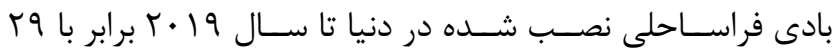

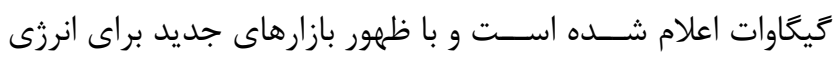

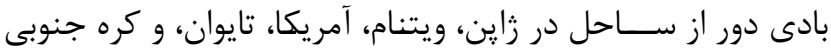

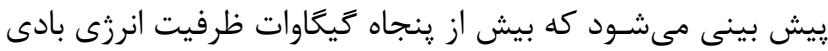

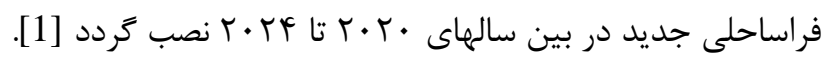

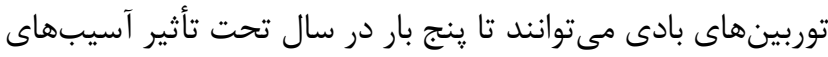

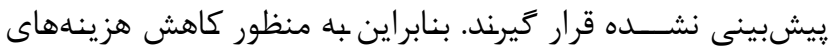

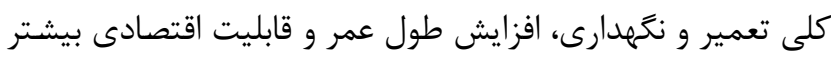
توربينها، سازه رامىبايست به طور مداوم تحت بِايش سلامت قرار

داد [2]

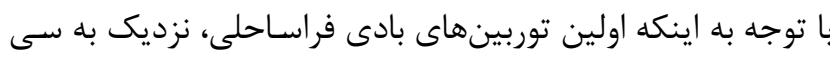

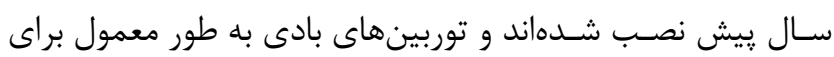
عمر بين بيست تا بيست و وينج سال طراحى مىشوند [3]، درحال

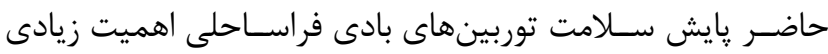

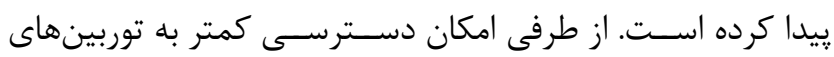
بادى دريايى نســبت به توربينهاى بادى واقع در خشـكى در كنار

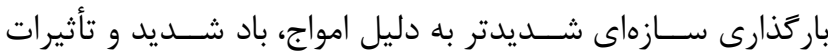

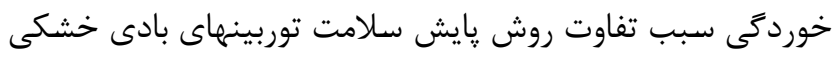

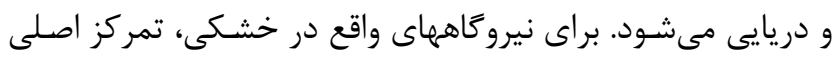

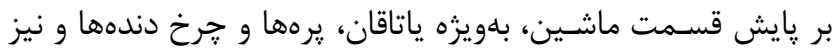

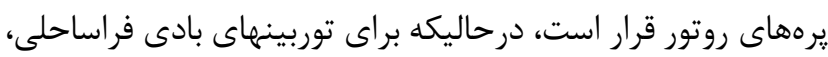

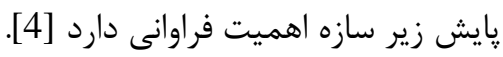

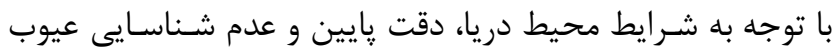

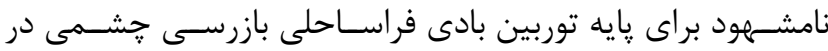

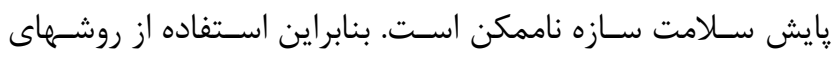

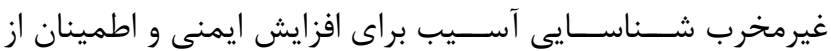


مرحلهاى را براى شــناسـايى دقيق موقعيت و شـدت آسـيبهاى

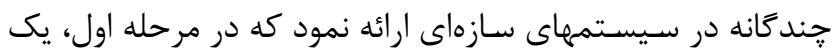

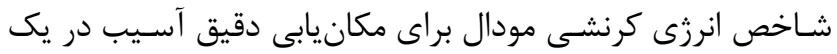

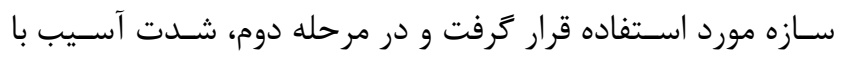

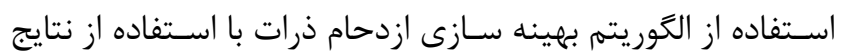

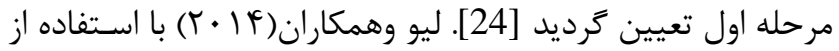
تفاضـل انرزى كرنشى مودال سـازه در حالت سـالم و آسـيب ديده،

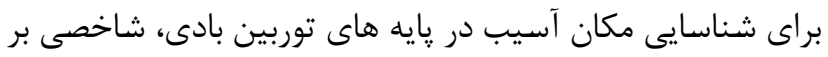

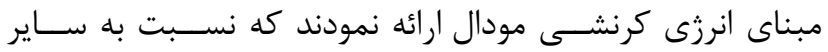
روشهاى سنتى انرزى كرنشى حساسيت بالاترى داشت [25]. سيد

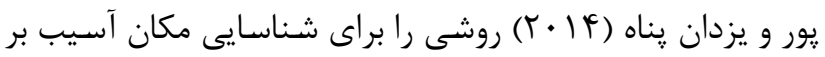

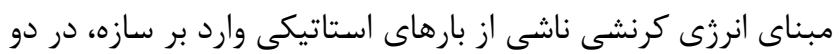

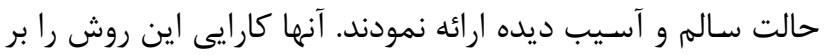
روى يك خرياى سـيزده عضـوى، يك قاب سـهـ دهانهاى و يكى خرياى فضايى بررسى نموده و به اين نتيجه رسيدند كه با اعمال

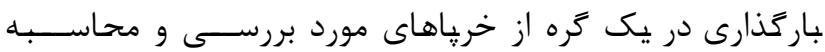

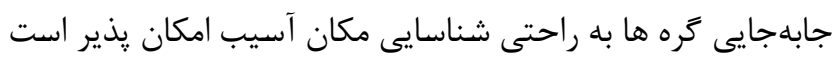

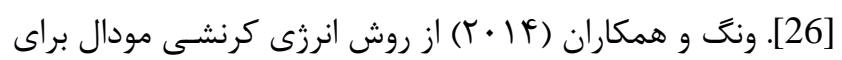
مكانيابى آسيب بر روى يك سكوى دور از ساحل استفاده كردند و

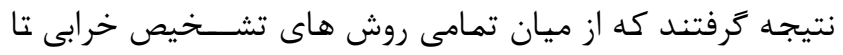

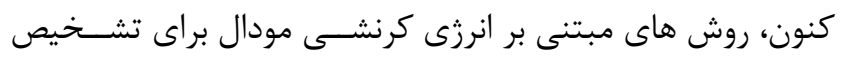

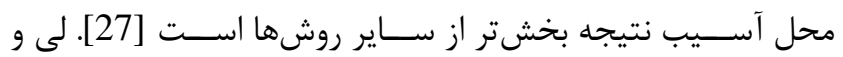

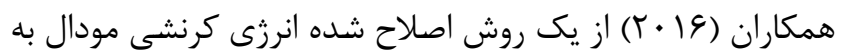

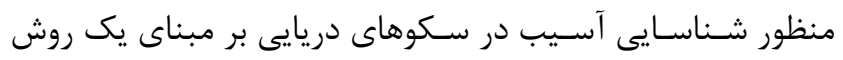

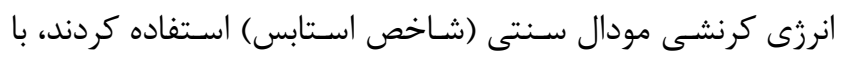
اين تفاوت كه فركانسهاى مودال را نيز در بررســى خود در نظر آنس

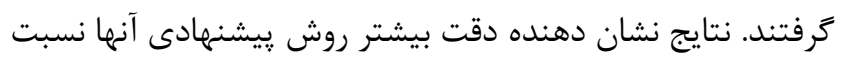

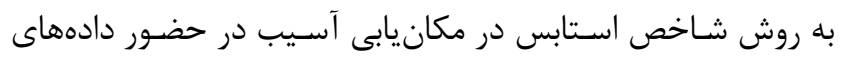

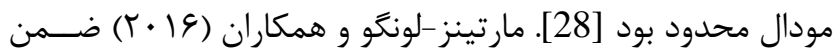

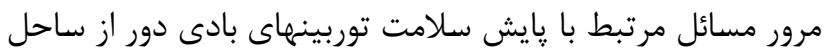

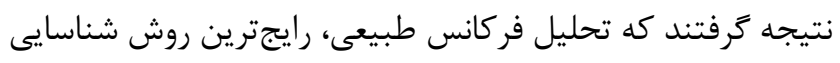

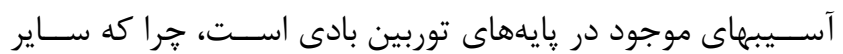
روشـها بسـيار يرهزينه، با بلوغ كم يا دقت ناكافى هســتند [29].

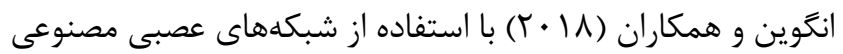

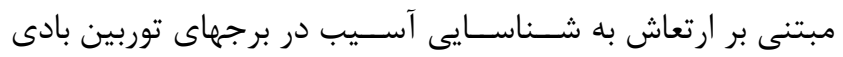

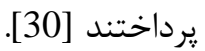

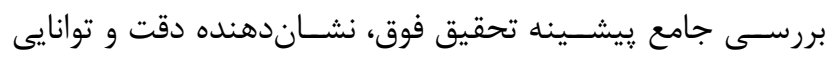

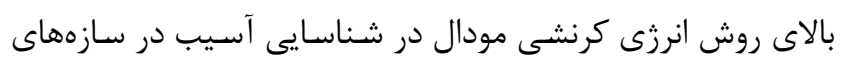

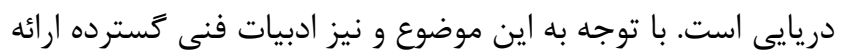

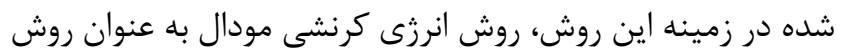

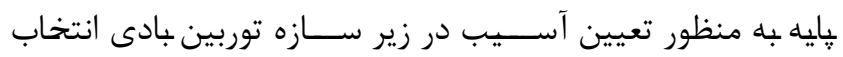

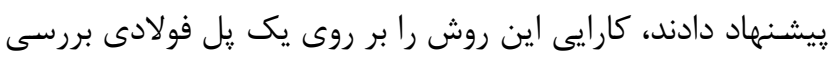

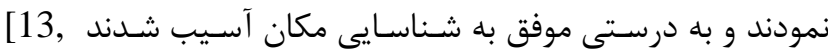

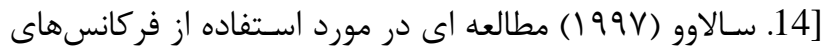

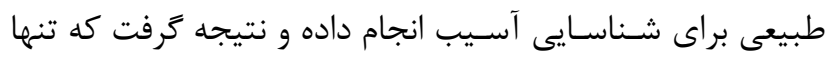
استفاده از فر كانسهاى طبيعى براى شناسايى موضعى آسيب كافى نيست، هر جند در شناسايى كلى آسيب مىتواند مؤثر باشد [15].

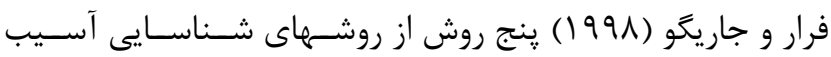

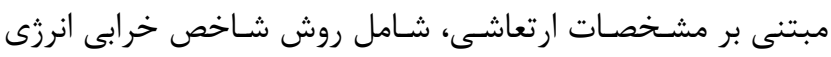
كرنشى مودال، روش انحناى شـكل مودى، روش تغيير در انعطاف يذيرى، روش تغيير در انحناى بار يكنواخت سـطحى و روش تغيير

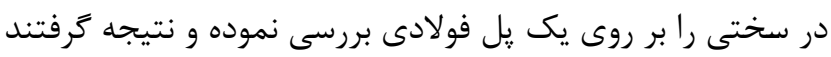

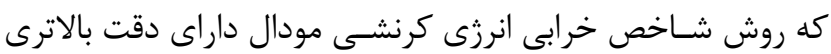

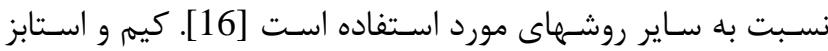

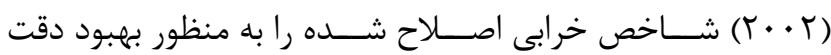

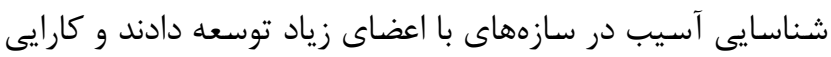
آن را بر روى يك تير دو دهانه آزمايش نمودند [17]. جنــ و و

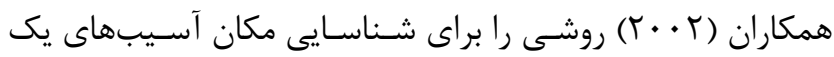

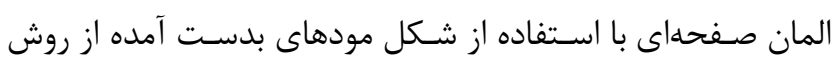

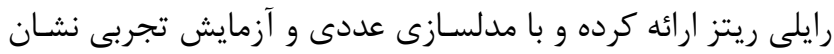

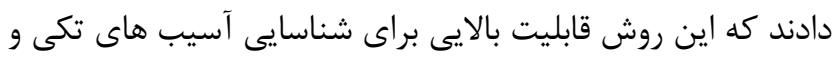

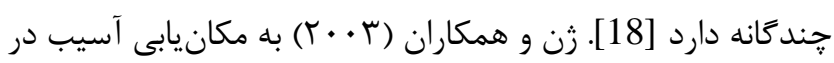

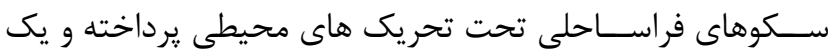

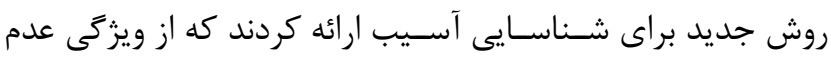

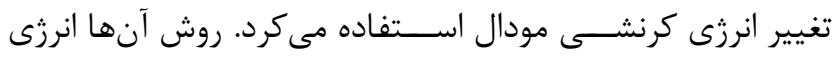

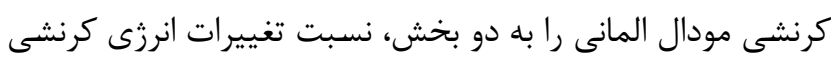

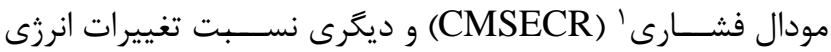

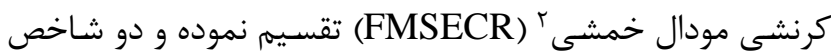

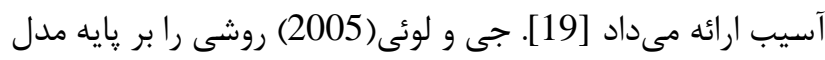

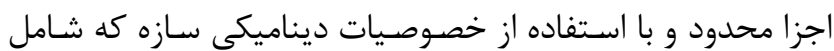

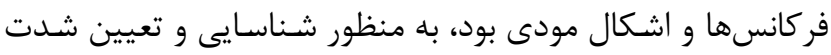

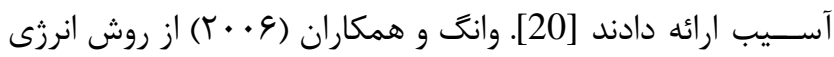

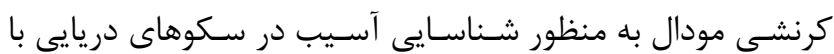
استفاده از داده هاى مودال ناقص (تنها دو شكل مود اول) استفادها

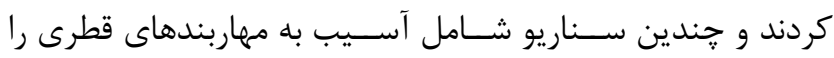

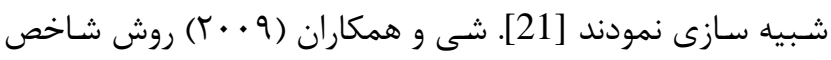

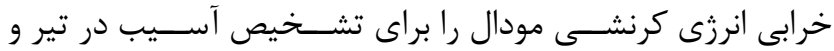

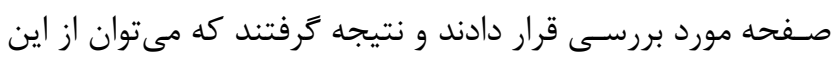

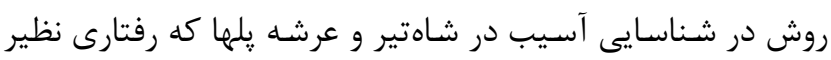

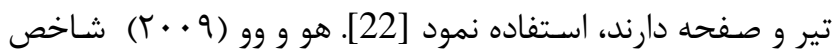

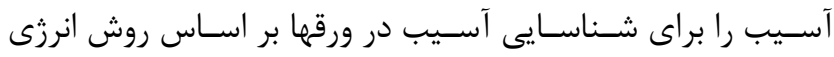

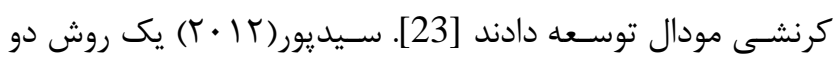


تريياد

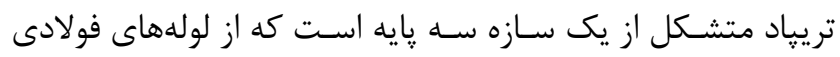

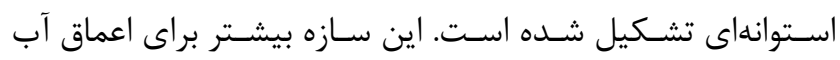

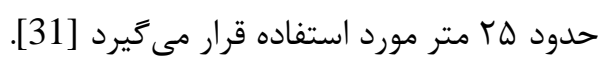

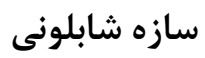

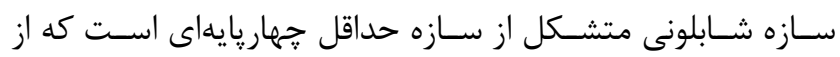

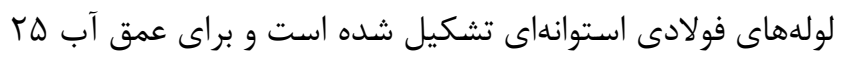

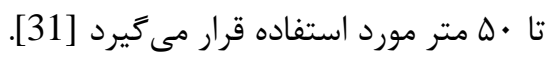

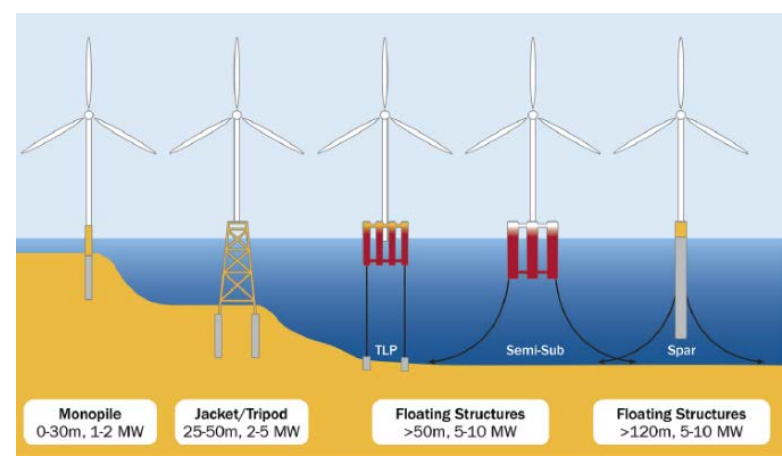

شكل ا انواع فونداسيون موجود براى توربينهاى بادى دور از ساحل

.[32]

r- آسيب ناشى از خوردكى در زيرسازه توربين بادى

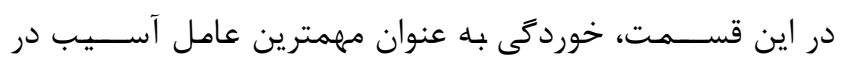

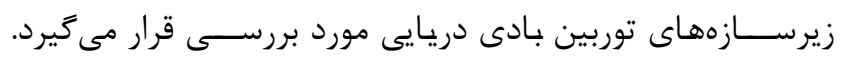

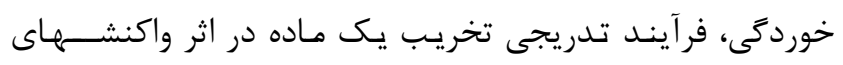

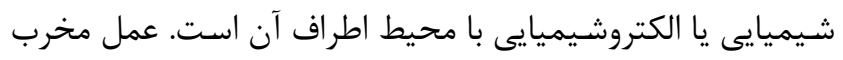

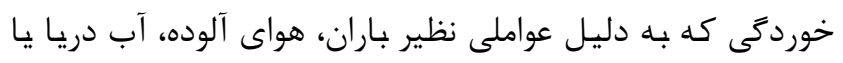

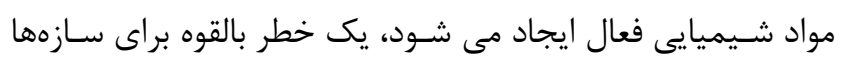
است، جرا كه ممكن است سبب از دست رفتن مواد شده و بنابراين ظرفيت بار نهايى سازه و به طور بالقوه، ايمنى آن را تحت تاثير قرار دهد. خورد

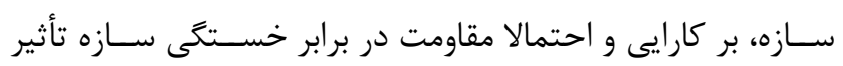
كذاشـته و از طريق حفره يا ايجاد شـكافهايى سـبب ايجاد سـوراخ شود و در نتيجه بر ظرفيت اقدامات مهارى اثر گذار باشد. خوردگى إنى

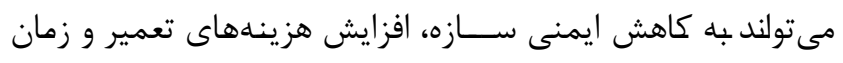

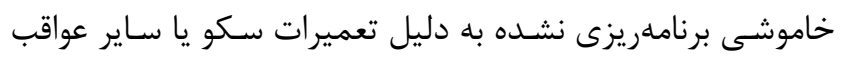

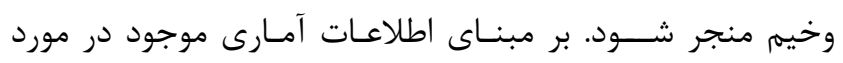

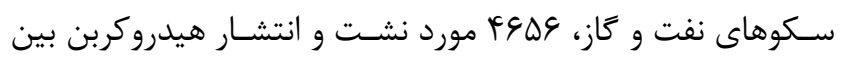

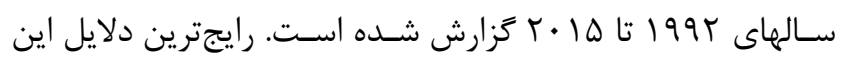
حوادث ناشى از شكست مكانيكى ناشى از خوردكى و ساير عوامل تخريب مرتبط است [33]

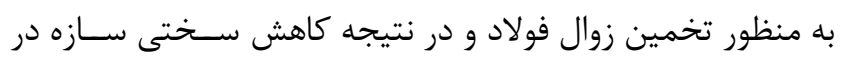

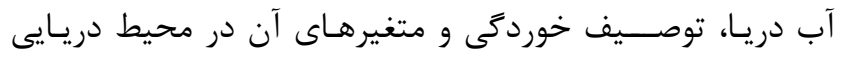
خورنده ضـرورى اسـت. تخريب ناشـى از خوردگى مى تواند به نحو
گرديد. همجنين اين روش تشــخيص غيرمخرب اسـت و در ميان روشهاى غيرمخرب ديخر مانند تسـتهاى UT و PT هزينه بسـيار كمتر و زمانبرى كمترى دارد. در اين تحقيق به شـناسـيى مكان و تعيين ميزان آسـيب زير سـازه شـابلونى توربين بادى فراسـاحلى به روش انرزى كرنشى مودال اصلاح شده يرداخته خواهد شد. موضوع

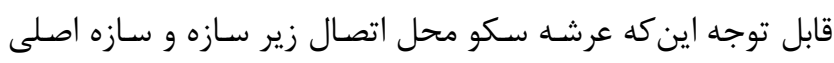

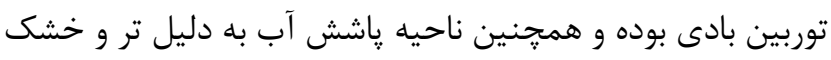

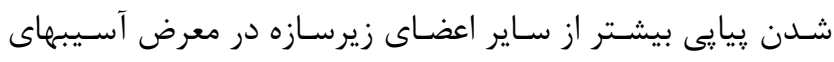

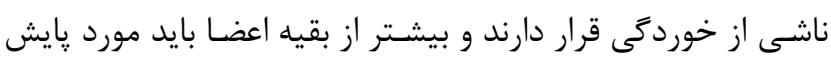

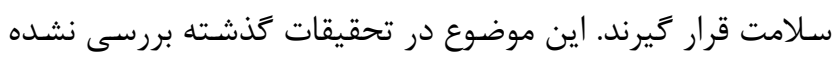

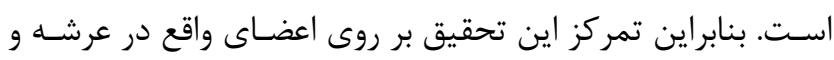
ناحيه ياشش آب است.

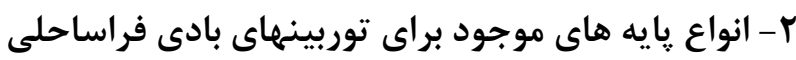
تاكنون، بيشتر زيرسازههاى استفاده شده براى توربينهاى بادى دورى دور بوري

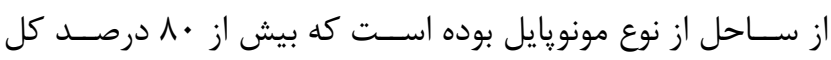

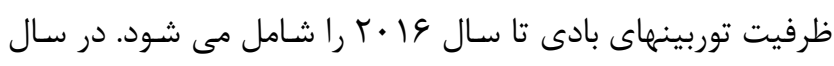

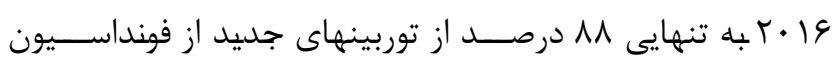
مونويايل و در r ا درصـد ديخر از سـكوهاى شــابلونى جهاريايه و

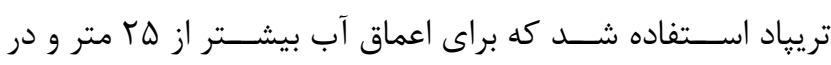

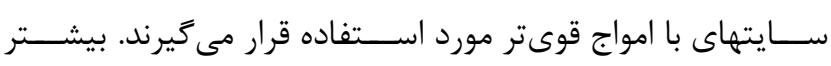

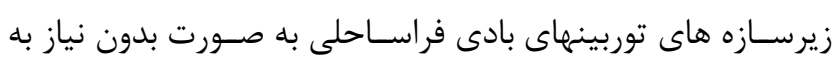

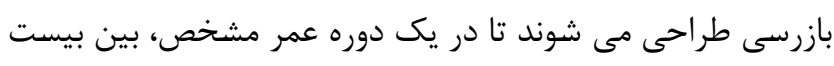

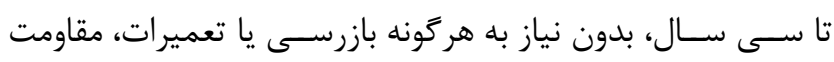

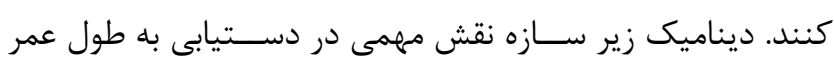

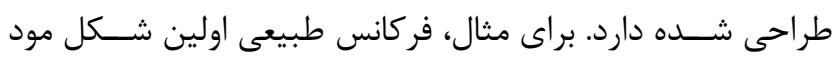

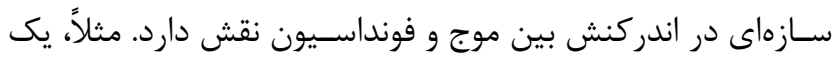
طراحى با فر كانس رزونانس يايينتر، در برابر ارتعاش ناشى از امواج

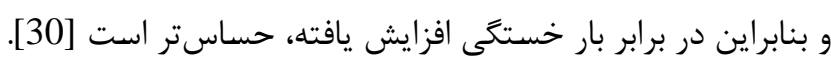

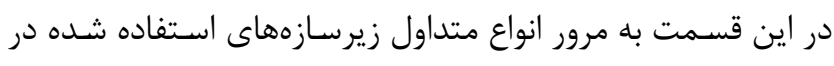

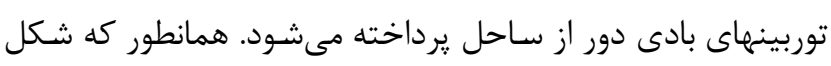

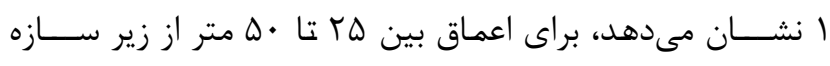

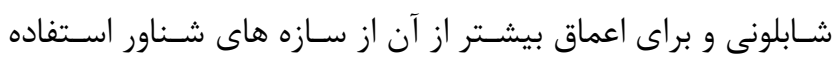
مونى شود.

اين نوع زير سازه توربين بادى داراى طراحى سادهاى بوده و از يكى

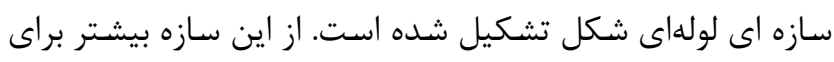

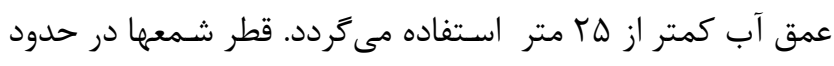

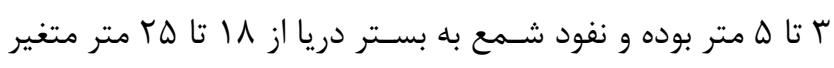

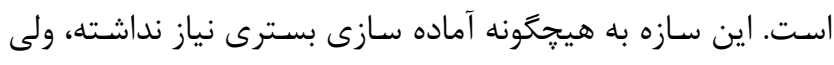

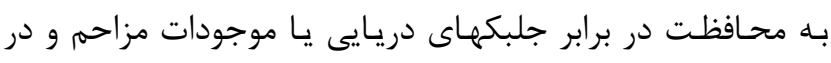
واقع عوامل فولينت روى سطح خود نياز دارد [31]. 


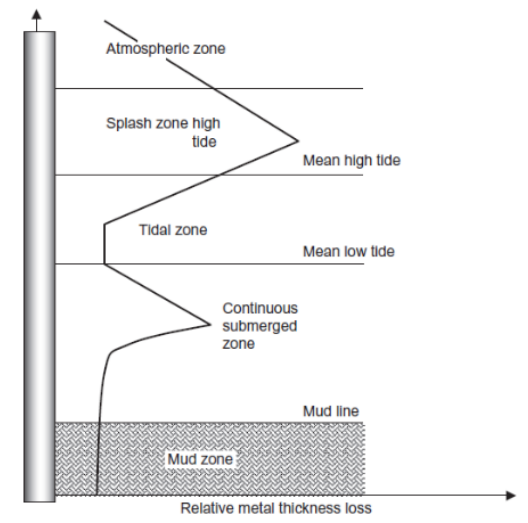

شكل r يروفيل خوردكى يك شمع فولادى يس از ه سال قرار كرفتن در محيط دريايى [37].

\section{F - انرزى كرنشى مودال}

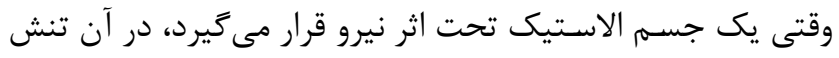

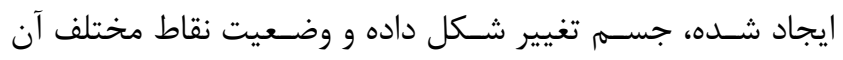

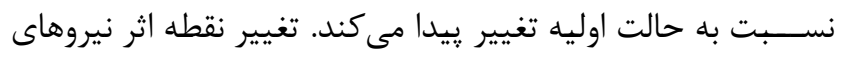

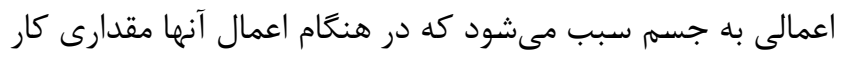

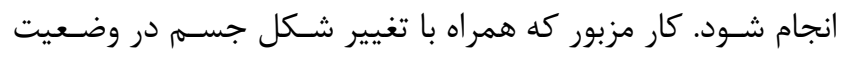

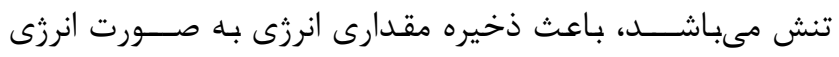

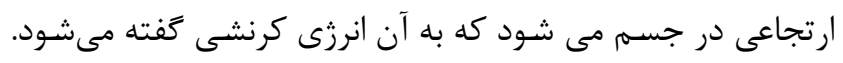

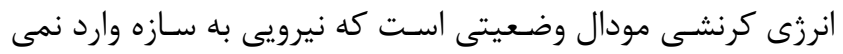

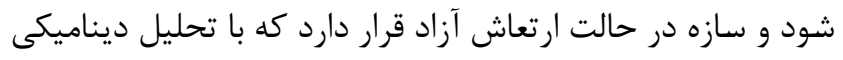

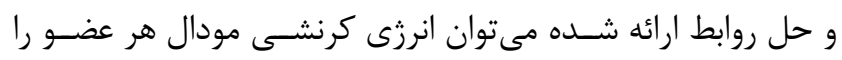
بدست آورد. خر ابى در يك سازه معمولا سبب كاهش سخت سختى ساز سرازه مىشود و بر ماتريس جرم سازه تاثيرى نمى درّارد.

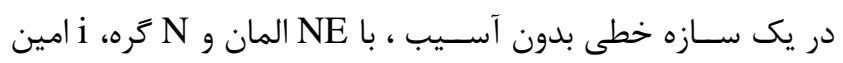
سختى مودال سازه از رابطه زير بدست مى آيد [117]:

$$
K_{i}=\phi_{i}^{T} C \phi_{i}
$$

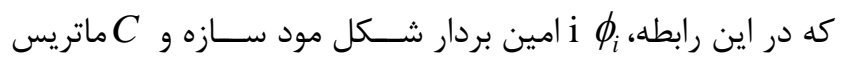

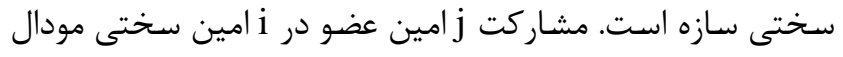
از رابطه زير بدست خواهد آمد.

$$
K_{i j}=\phi_{i}^{T} C_{j} \phi_{i}
$$

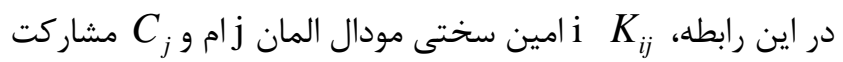
المان j ام در ماتريس سختى سازه است.

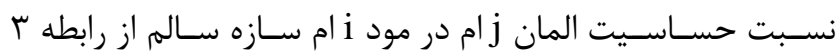

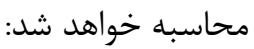

$$
F_{i j}=\frac{K_{i j}}{K_{i}}
$$

همين نسبت براى سازه در حالت آسيب برابر است با:

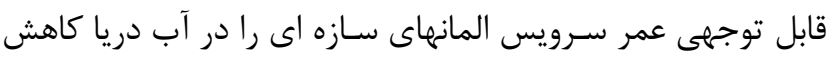
دهد. براى حفاظت در برابر خوردگى، معمولا از يوشـشهاى محافظ إنظ

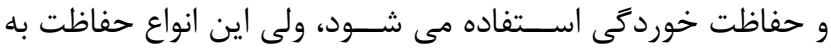

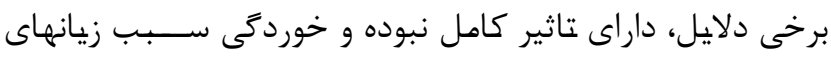

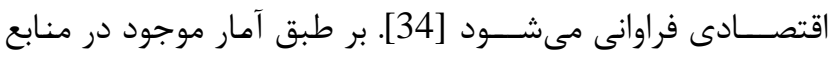

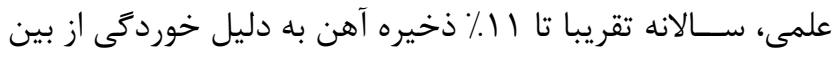

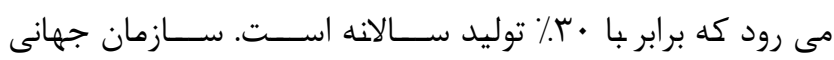

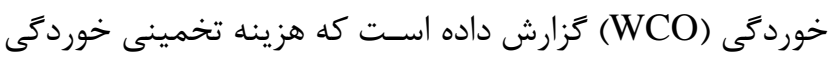

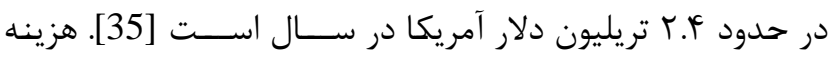

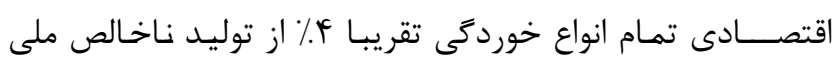

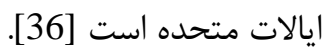

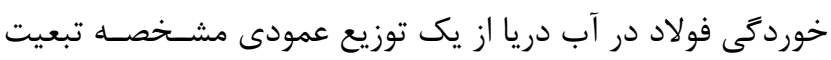

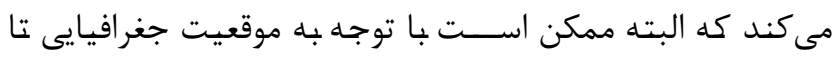

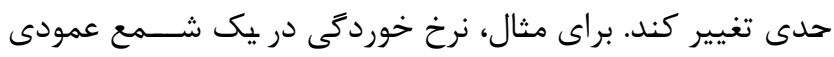

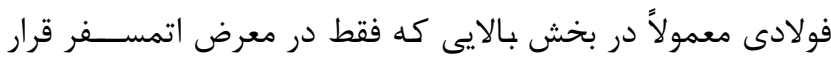

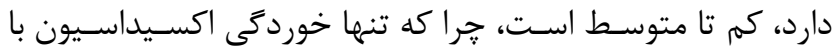

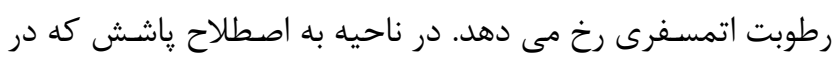

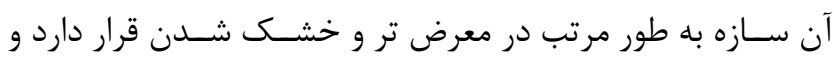

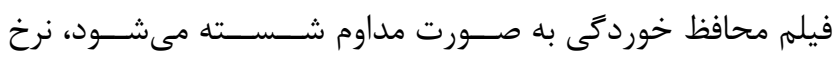

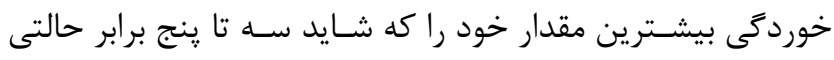

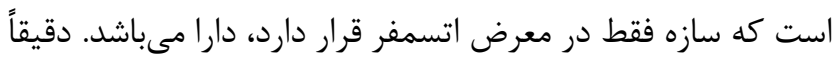

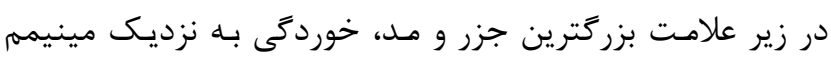

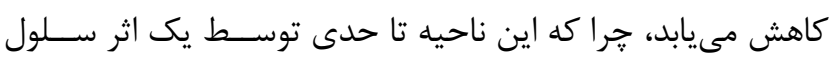

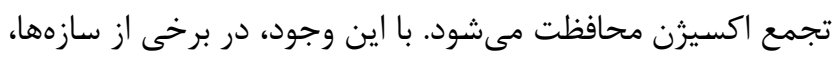

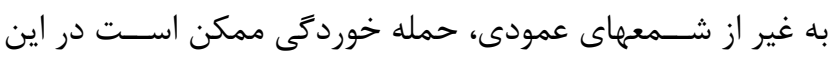

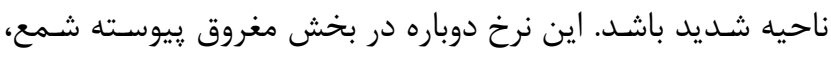

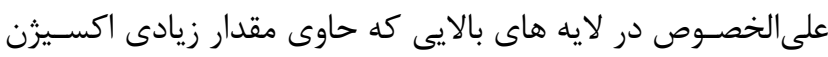

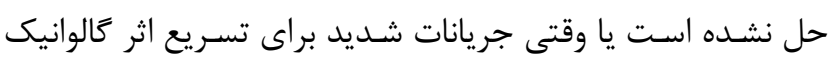

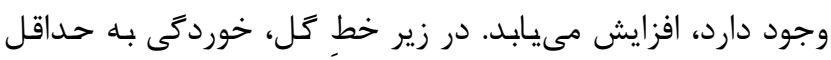

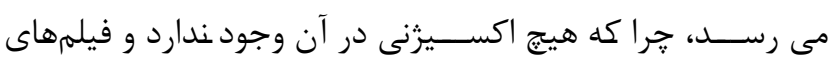

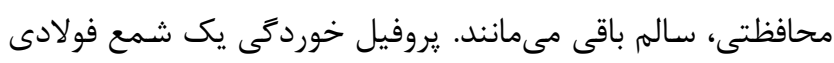

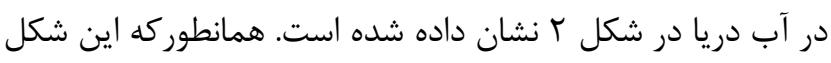

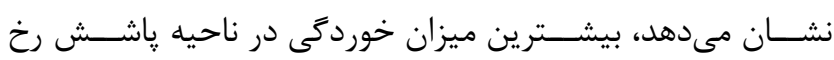




$$
\begin{aligned}
1= & \frac{F_{i j}^{*}+1}{F_{i j}+1} \\
& : \frac{\left(K_{i j}^{*}+K_{i}^{*}\right) K_{i}}{\left(K_{i j}+K_{i}\right) K_{i}^{*}}
\end{aligned}
$$

در صورت جايگذارى معادلات ل، r، ه و 4 در معادله بالا براى تمام

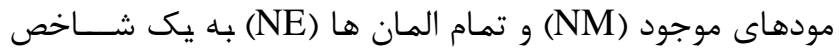
آسيب براى هر المان مىرسيم كه خوداهيهم داشت:

$$
\beta_{j}=\frac{\sum_{i=1}^{N M}\left(\phi_{i}^{* T} C_{j o} \phi_{i}^{*}+\sum_{i=1}^{N E} \phi_{i}^{* T} C_{k o} \phi_{i}^{*}\right) K_{i}}{\sum_{i=1}^{N M}\left(\phi_{i}^{T} C_{j o} \phi_{i}+\sum_{i=1}^{N E} \phi_{i}^{T} C_{k o} \phi_{i}\right) K_{i}^{*}}
$$

لازم به ذكر است كه بدليل مشخص نبودن ماتريس سختى سازه و

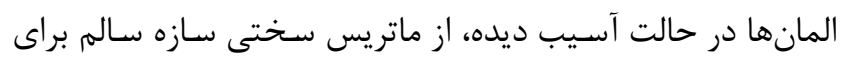

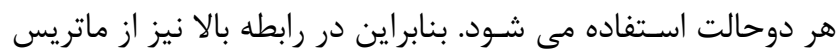
سختى سازه سالم استفاده شده است.

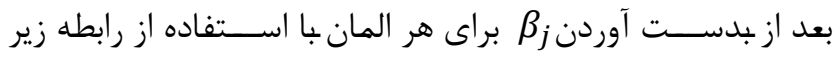

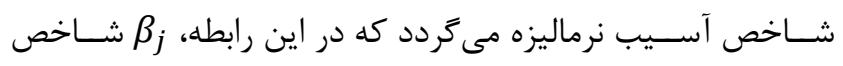

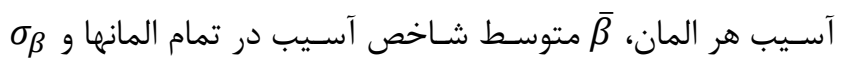
انحراف معيار شاخص آسيب بوده و $Z_{j}$

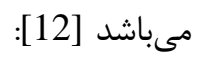

$$
Z_{j}=\frac{\beta_{j}-\bar{\beta}}{\sigma_{\beta}}
$$

\section{روش انرزى كرنشى مودال اصلاح شده (IMSE)} در تعيين شـاخص خرابى اسـتابس تنها از شـكل مودها اسـتفاده مىشـــود و فركانسهاى طبيعى در تعيين محل آســيـ در در نظر كرفته نمى شـوند. با اين وجود، تحقيقات قبلى نشـان داده اسـت كه

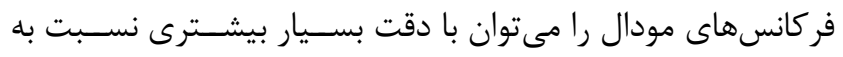

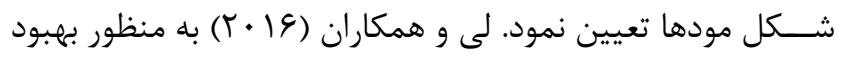

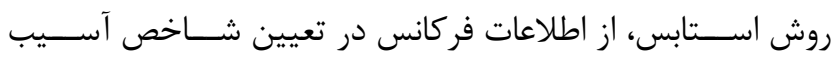

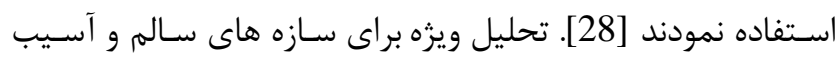
ديده را مىتوان به صورت زير نوشت:

$$
\begin{aligned}
& K \phi_{i}=\omega_{i}^{2} M \phi_{i} \\
& K^{*} \phi_{i}^{*}=\omega_{i}^{* 2} M^{*} \phi_{i}^{*}
\end{aligned}
$$

در اين رابطه، Mو $M^{*}$ ماتريسهاى جرم سيستم در حالتهاى سالم و آســـيب ديده بوده و

$$
F_{i j}^{*}=\frac{K_{i j}^{*}}{K_{i}^{*}}
$$

كه

$$
\begin{aligned}
& K_{i}^{*}=\phi_{i}^{* T} C^{*} \phi_{i}^{*} \\
& K_{i j}^{*}=\phi_{i}^{* T} C_{j}^{*} \phi_{i}^{*}
\end{aligned}
$$

در روابط فوق، علامت ** نشانگر حالت آسيب ديده است. با تقسيم معادله f بر معادله ب داريم :

$$
\frac{F_{i j}^{*}}{F_{i j}}=\frac{K_{i j}^{*} K_{i}}{K_{i j} K_{i}^{*}}
$$

مقدار $C_{j}$

$$
\begin{aligned}
& C_{j}=E_{j} C_{j o} \\
& C_{j}^{*}=E_{j}^{*} C_{j o}
\end{aligned}
$$

كه

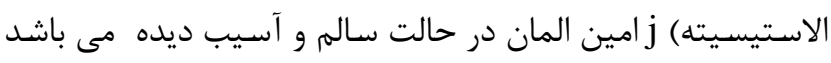

$$
\text { و تنها مشخصات هندسى را در بر مى }
$$
اگر ميزان آسـيب در سازه كوجى باشد معادله V برابر واحد خواهد شد در نتيجه : n (1) - n

$$
F_{i j}=F_{i j}^{*}
$$

با جايگزين كردن معادلات ل، ؟، ه، و و ^ در معادله لو بازنويسى

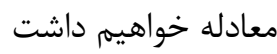

$$
\beta_{i j}=\frac{E_{j}}{E_{j}^{*}}=\frac{\left[\phi_{i}^{* T} C_{j o} \phi_{i}^{*}\right] K_{i}}{\left[\phi_{i}^{T} C_{j o} \phi_{i}\right] K_{i}^{*}}
$$

در اين رابطه، امين مود است. جنانجه در سمت راست ( از جمله $\phi_{i}$ و يارامترهاى مودال به دست آمده از اندازهَيريهاى تجربى و هندسه سازه (

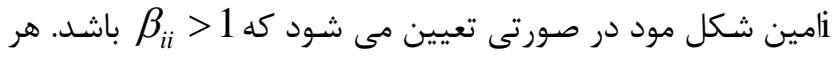

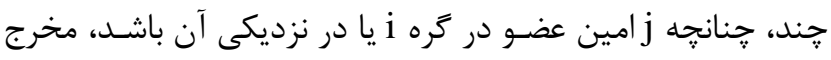
معادله فوق به سـمت صـفر مىرود ( 1 (>1

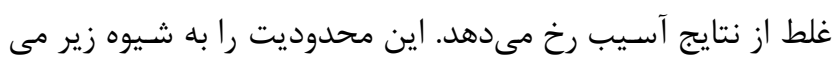

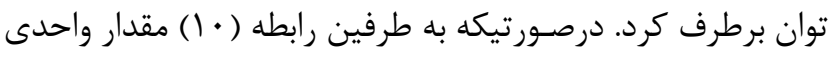
را اضافه كنيم خواهيم داشت: 
ه- تشــخيص مكان و شـدت آســيب در سـكوى شــابلونى توربين بادى

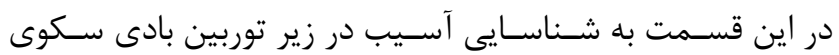
جهاريايه شـابلونى JX كه در شـكل r نشـان داده شـده، ترداخته مىشـود. اين سـكو كه يكى از متداولترين سـكوهاى يايه توربين بادى است، داراى ارتفاع و4 مترى و مقطع متوازى الاضلاع است. بر مبناى تحقيق انجام شده توسط جن و همكاران [38]، اين نوع زير

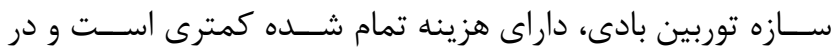

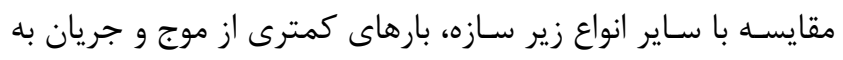

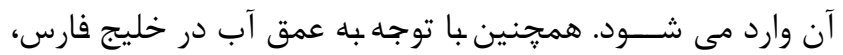
مناسـبترين קايه توربين بادى براى اين منطقه نيز سـازه شـابلونى

مذكور مى باشد. اطلاعات سكو در جدول ا آورده شده است [38].

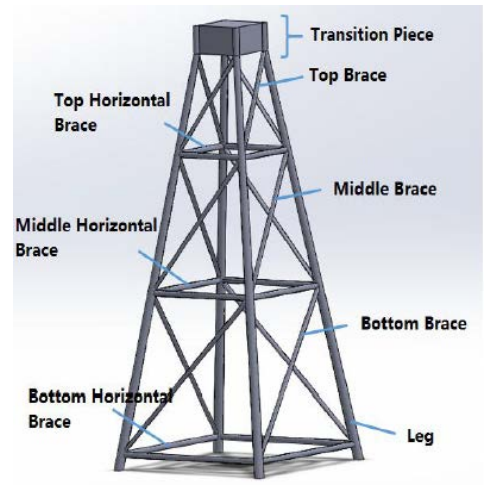

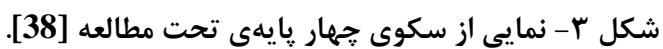

جدول ا مشخصات سكوى شابلونى J8] [38].

\begin{tabular}{|c|c|}
\hline Jجهاريايه JX & نوع سكوى شابلونى \\
\hline (991. 9 متر & ارتفاع كلى \\
\hline 9V/9V متر & طول پايه \\
\hline 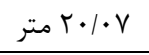 & طول مهاربند بالايى \\
\hline TH/QF & طول مهاربند ميانى \\
\hline 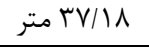 & طول مهاربند يايينى \\
\hline 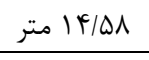 & طول مهاربند افقى بالايى \\
\hline ( TY/TY & طول مهاربند افقى ميانى \\
\hline " & طول مهاربند افقى پايينى \\
\hline ب.|• متر & ضخامت مهاربند \\
\hline |f & ضخامت پايه \\
\hline • • • متر & قطر مهاربند \\
\hline إ/1/ متر & قطر پِايه \\
\hline
\end{tabular}

و- اعمال آسـيب فرضسى بر روى سـازه و تعريف سـناريو هاى مختلف آسيب به منظور شــناسـايى آســيب در ســازه، برنامه اى به روش المان

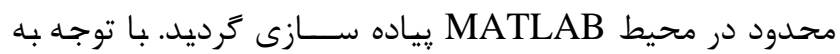
كاهش مشـخصات مصـالح سـازه در صـورت آسـيبديدگى، آسـيب
به طور كلى، آسيبهاى موضعى سبب كاهش سختى سازه شده و

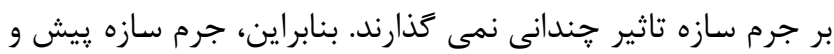
يس از آسـيب بايد يكسـان باشـد، به طورى كه

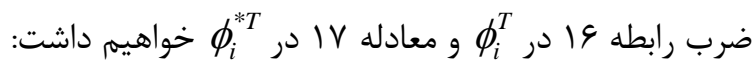

$$
\begin{gathered}
S_{i}=\phi_{i}^{T} K \phi_{i}=\omega_{i}^{2} \phi_{i}^{T} M \phi_{i} \\
S_{i}^{*}=\phi_{i}^{* T} K^{*} \phi_{i}^{*}=\omega_{i}^{* 2} \phi_{i}^{* T} M \phi_{i}^{*}
\end{gathered}
$$

در صـورت يكسـان بودن مصـالح تشـكيل دهنده، تمام اعضـاء سـازه

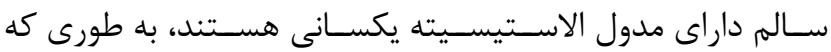
E $E$ for $j=1,2, \ldots, n e$

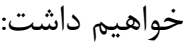

$$
\beta_{j}=\frac{\sum_{i=1}^{m}\left(\phi_{i}^{* T} K_{j} \phi_{i}^{*}+\phi_{i}^{* T} K \phi_{i}^{*}\right) S_{i}}{\sum_{i=1}^{m}\left(\phi_{i}^{T} K_{j} \phi_{i}+\phi_{i}^{T} K_{j} \phi_{i}\right) S_{i}^{*}}
$$

وقتى خرابى بـه صـــورت موضـــى رخ مى دهـد، رابطـه تقريبى $S_{i}^{*}=\phi_{i}^{* T} K^{*} \phi_{i}^{*} \approx \phi_{i}^{* T} K \phi_{i}^{*}$ خرابى Stubbs را مىتوان به صورت زير تخمين زد:

$$
\beta_{j}=\frac{\sum_{i=1}^{m}\left(\phi_{i}^{* T} K_{j} \phi_{i}^{*}+S_{i}^{*}\right) S_{i}}{\sum_{i=1}^{m}\left(\phi_{i}^{T} K_{j} \phi_{i}+S_{i}\right) S_{i}^{*}}
$$

با جايگزينى معادلات 1 | و 9 در رابطه اب داريم:

$$
\beta_{j}=\frac{\sum_{i=1}^{m}\left(\phi_{i}^{* T} K_{j} \phi_{i}^{*}+\omega_{i}^{* 2} \phi_{i}^{* T} M \phi_{i}^{*}\right) \omega_{i}^{2} \phi_{i}^{T} M \phi_{i}}{\sum_{i=1}^{m}\left(\phi_{i}^{T} K_{j} \phi_{i}+\omega_{i}^{2} \phi_{i}^{T} M \phi_{i}\right) \omega_{i}^{* 2} \phi_{i}^{* T} M \phi_{i}^{*}}
$$
مجدداً مى توان با اســـفاده از رابطه VVا، شــاخص فوق را نرماليزه نمود. تخمين شدت آسيب شدت آسيب را مىتوان مستقيماً از معادله 1 ا تعيين نمود. جنانجه نسبت تغييرات در سختى عضو j ام را با d $\alpha_{j}$ نشان دهيم بهطوريكه ب $\alpha_{j} \geq-1$

$$
E_{j}^{*}=E_{j}\left(1+\alpha_{j}\right)
$$

با تركيب معادلات || 19 و خواهيم داشت:

$$
\alpha_{j}=\frac{\left[\phi_{i}^{T} C_{j o} \phi_{i}\right]}{\left[\phi_{i}^{* T} C_{j o} \phi_{i}^{*}\right]} \frac{K_{i}^{*}}{K_{i}}-1
$$


الف
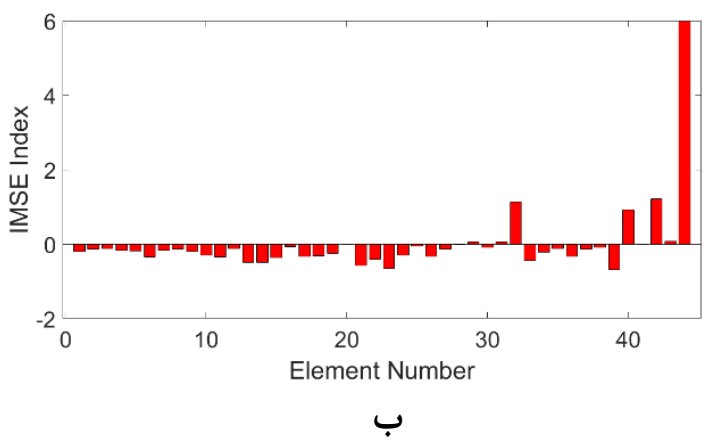

شكل ه تعيين محل آسيب با استفاده از روش شاخصهاى الف) استابس و ب) بهبوديافته در سناريوى اول.

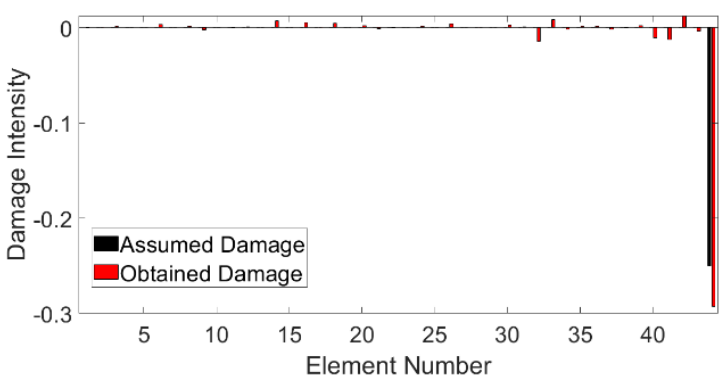

شكل 9 شدت خرابى فرض شده و به دست آمده با استفاده از روش انرزى كرنشى مودال در سناريوى اول

سناريوى دوم: در اين سناريو، المان شماره Fr به ميزان ادرصد دهار آسيب شده است. نمودار محل آسيب در شكل ل و نمودار شدت آسيب در اين

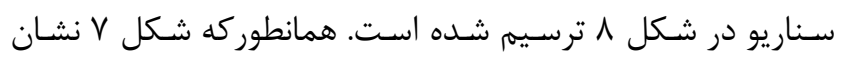

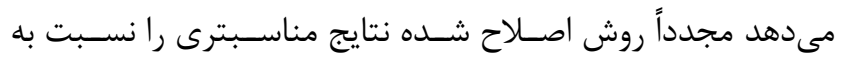
شـاخص اســتابس ارائه نموده اسـتـ، به طورى كه ميزان خطا در

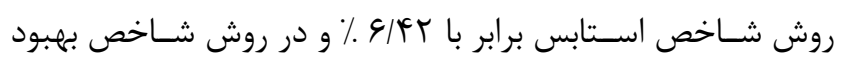

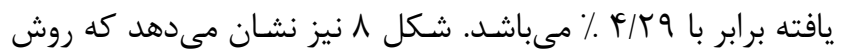

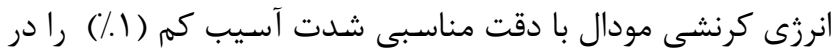

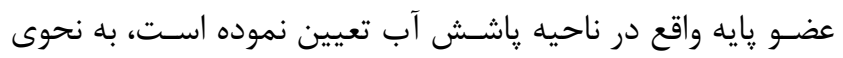

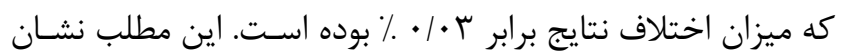

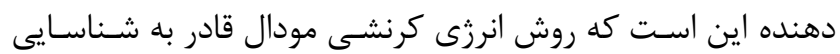
هر دو نوع آسيب هاى كمم و آسيب هاى زين اسي است است.

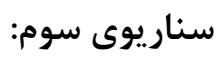
در اين حالت، فرض مىشـود كه عضو شـماره · f به عنوان يكى از اعضـاى مورب واقع در منطقه يُشــش به ميزان · ل درصــد دجار

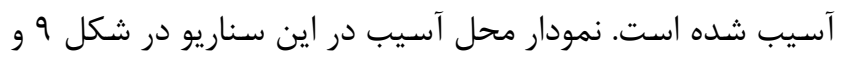

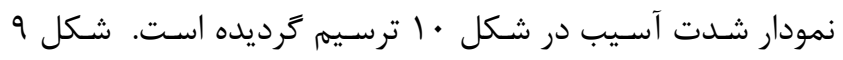
نشان دهنده بهبود دقت مكانيابى آسيب با استفاده از روش اصلاح شده نسـبت به شـاخص استابس است، به نحوى كه ميزان خطا در

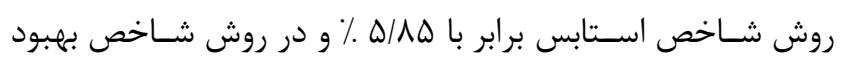

فرضى با كاهش مدول الاسـتيسـيته المان اعمال مى گردد. سـيس با تعريف سـناريوهاى مختلف آسـيب هاى تكى و جندتايى، به بررسى روش انرزى كرنشى مودال يرداخته مىشود. لازم به توضيح است، در تعريف ســاريوها سـعى شـده اسـت كه اعضـاى واقع در ناحيه ياشش و عرشه سكو مورد آسيب قرار گيرند. جدول r سـناريوهاى

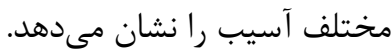

جدول r- سناريوهاى مختلف آسيب به سكوى شابلونى جهاريايه

\begin{tabular}{|c|c|c|}
\hline ميزان آسيب & شماره المان & شماره سناريو \\
\hline$\%$ r & pr & 1 \\
\hline$\% 1$ & MF & $r$ \\
\hline$\%$ & f. & $\mu$ \\
\hline$\%$ & Tr & r \\
\hline$\%$ r,$\%$ & Fr, MF & $\Delta$ \\
\hline
\end{tabular}

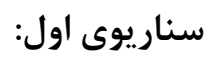

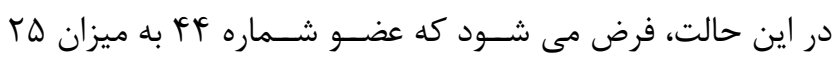

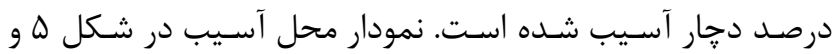
شدت آسيب در شكل 9 ترسيم گرديده است. همانطور كه شكله نشــان مى دهد، روش انرزى كرنشـى مودال با دقت بالايى قادر به

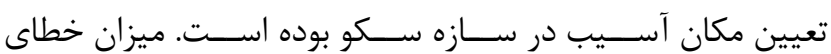
تشخيص مكان آسـيب با استفاده از روش شـاخص اسـتابس برابر با

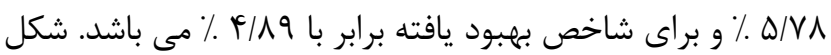

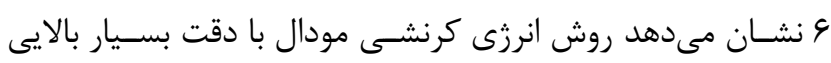

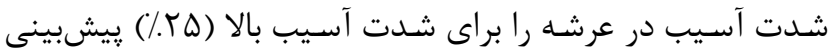
نموده اسـت، به طورى كه ميزان اختلاف نتايج در اين سـناريو برابر

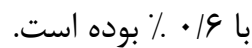

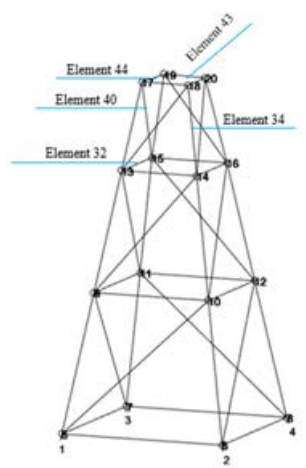

شكل F مدل ساخته شده سكوى JX در متلب و المانهاى فرضى آسيب ديده.

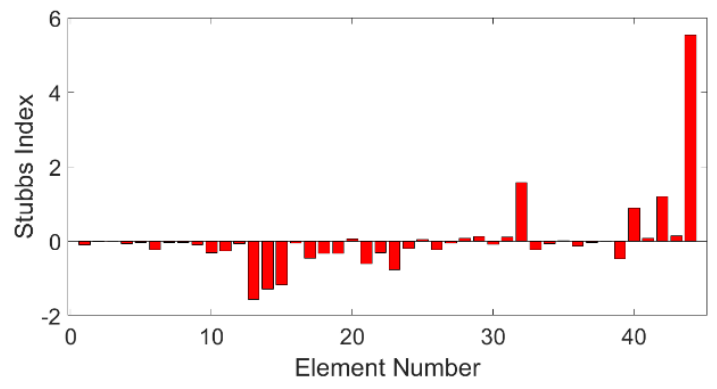


شكل ^ شدت خرابى فرض شده و به دست آمده با استفاده از روش انرزى كرنشى مودال در سناريوى دوم سده دسب

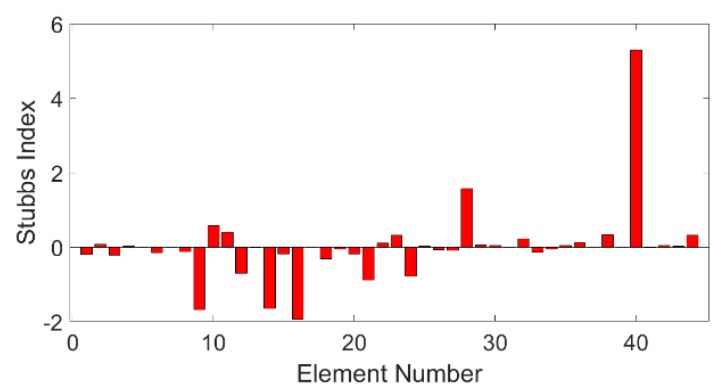

الف

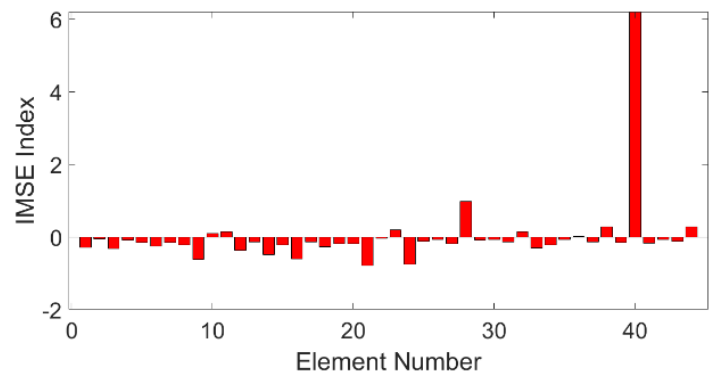

$\varphi$

شكل 9 تعيين محل آسيب با استفاده از روش شاخصهاى الف) استابس و ب) بهبوديافته در سناريوى سوم

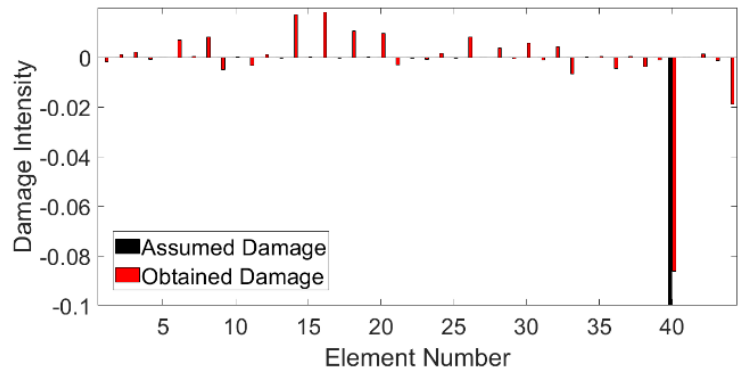

شكل •ا شدت خرابى فرض شده و به دست آمده با استفاده از روش انرزى كرنشى مودال در سناريوى سوم

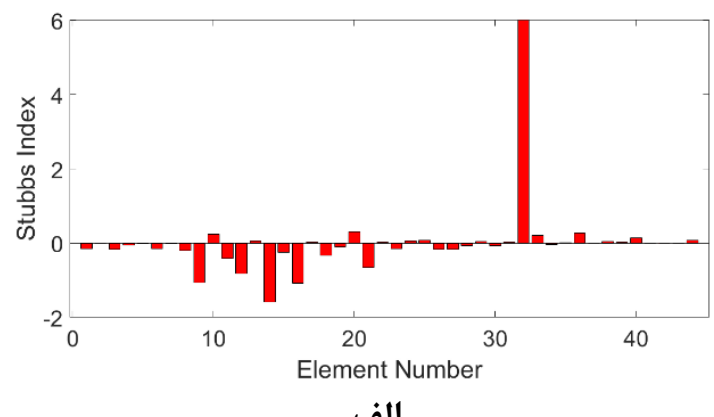

الف

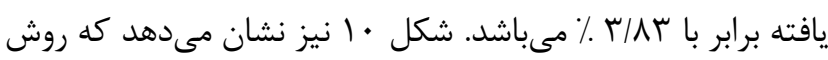
انرزى كرنشى مودال براى اعضاى مهاربند واقع در ناحيه ياشش نيز

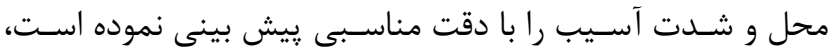

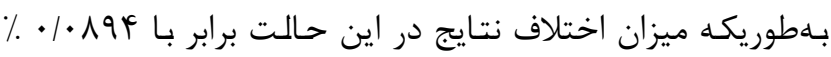
است.

سناريوى جههارم: - سمار در اين حالت، فرض مىشـود كه عضو شـماره r rا، به عنوان يكى از اعضاى افقى واقع در منطقه ياشش به ميزان • ادرصد دجار آسيب

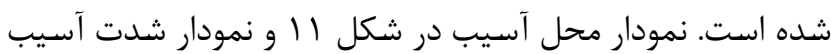

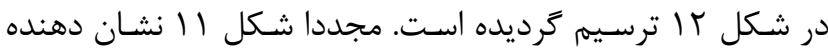
بهبود قابل توجه ييشبينى مكان آسـيب با استتفاده از روش اصلاح

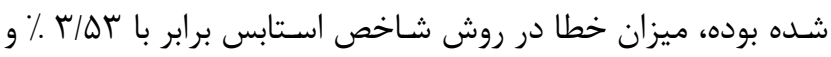

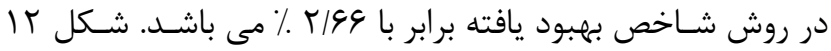

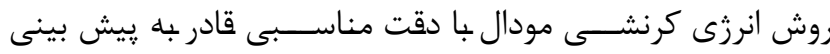

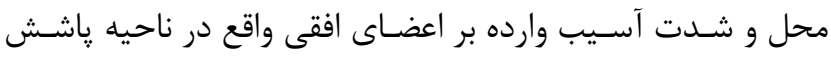
آب بوده است، ميزان اختلاف نتايج در اين حالت برابر با سو • • . ٪ مىباشد.
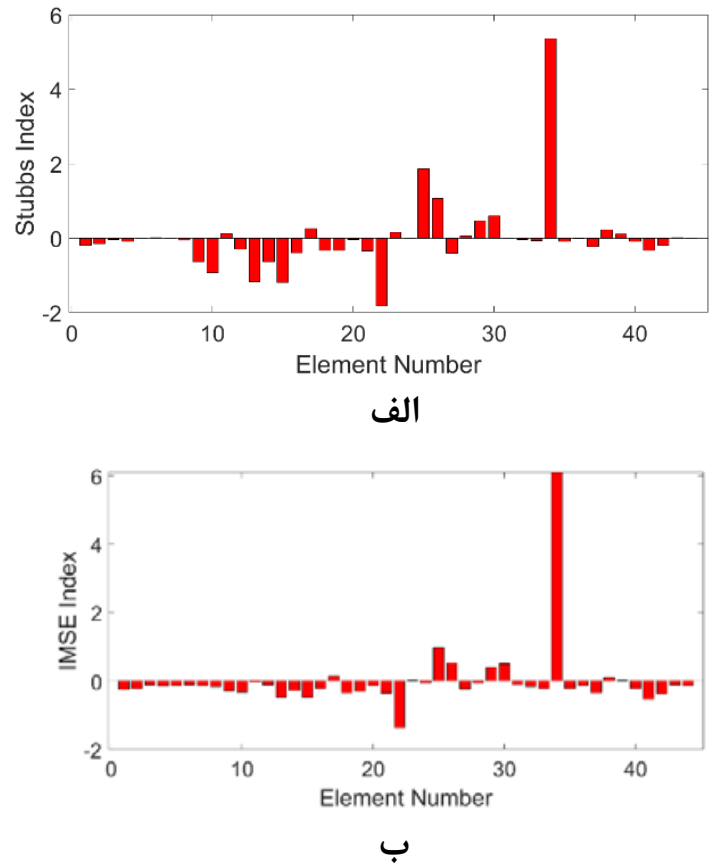

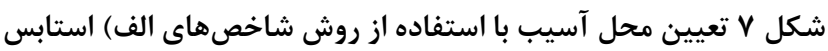
و ب) بهبوديافته در سناريوى دوم

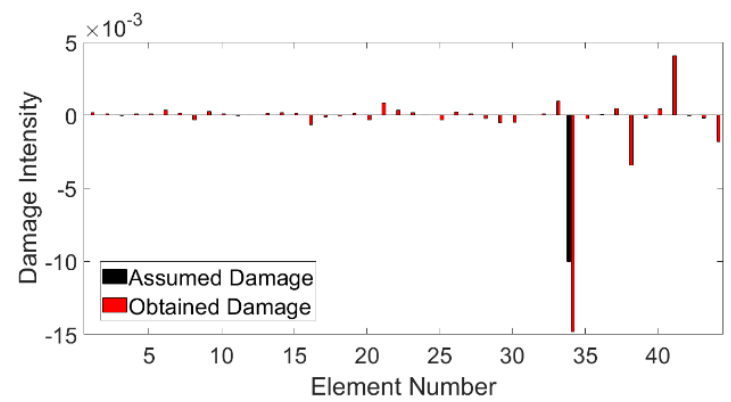




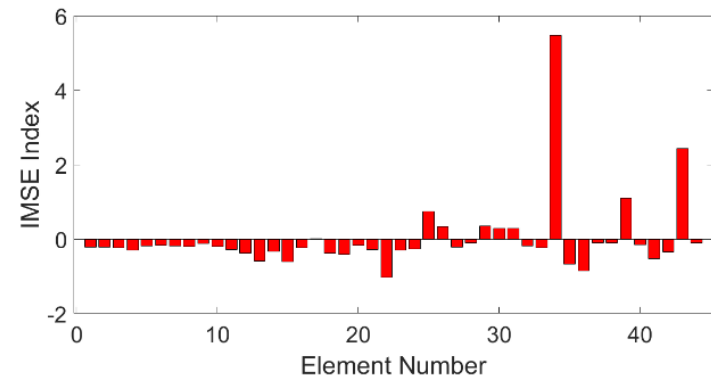

الف

شكل باتعيين محل آسيب با استفاده از روش شاخصهاى الف) استابس و ب) بهبوديافته در سناريوى ينجمه.

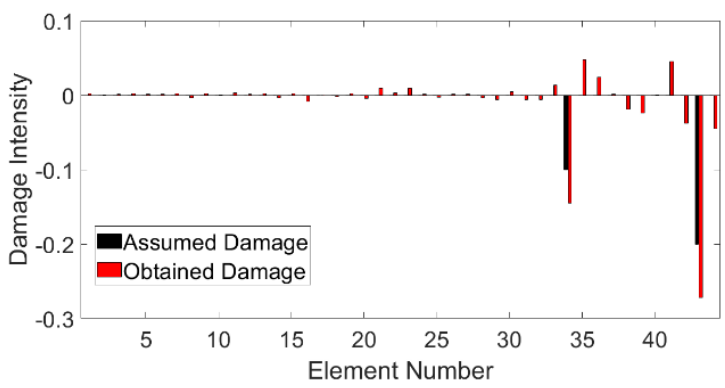

شكل ا تعيين شدت آسيب با استفاده از روش انرزى كرنشى مودال در سناريوى ينجم

\section{- Vتيجه خيرى - V}

با نزديك شــدن به عمر مفيد بهرهبردارى در توربينهاى بادى دور

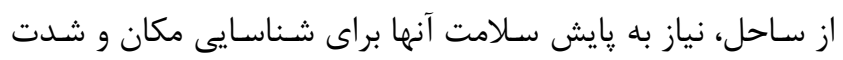

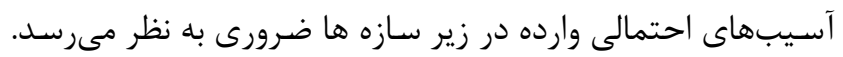

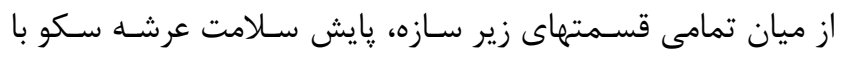

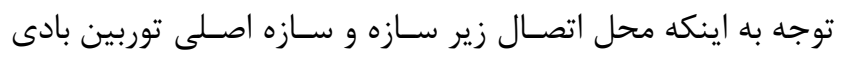

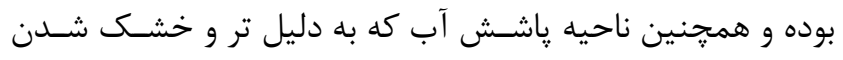

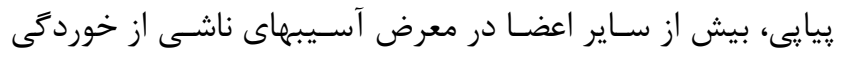

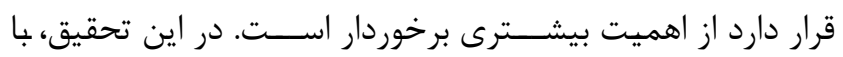

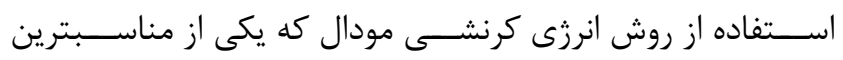
روشهاى شناسايى غير مخرب آسيب در سازه ها است، به شناسايى

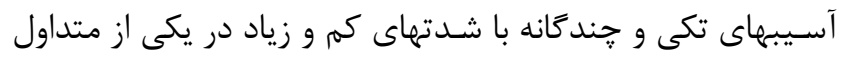

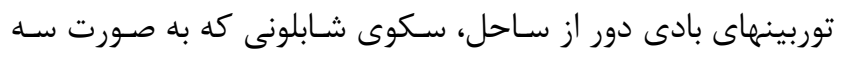

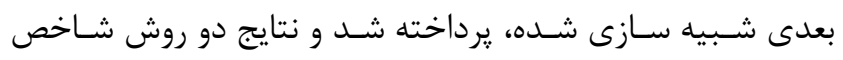
استابس و روش انرزى كرنشى مودال اصلاح شده با يكديخر مقايسه

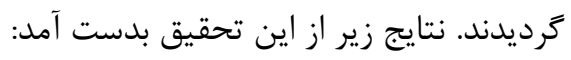

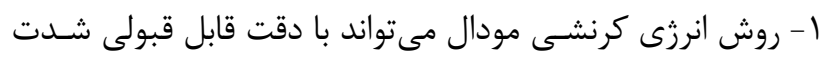

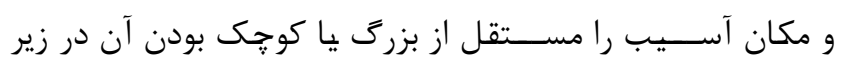
سازههاى توربين بادى فراساحلى شناسايى نمايد.

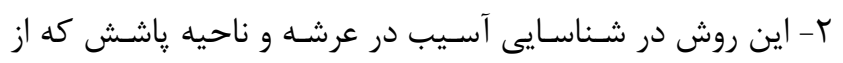
اهميت بيشـترى نسـبت به سـاير اعضـاى سـكو برخوردار بوده و از

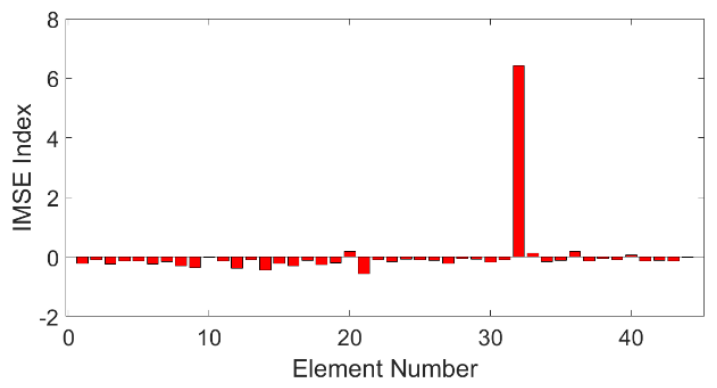

ب

شكل Iا تعيين محل آسيب با استفاده از روش شاخصهاى الف)

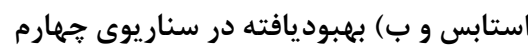

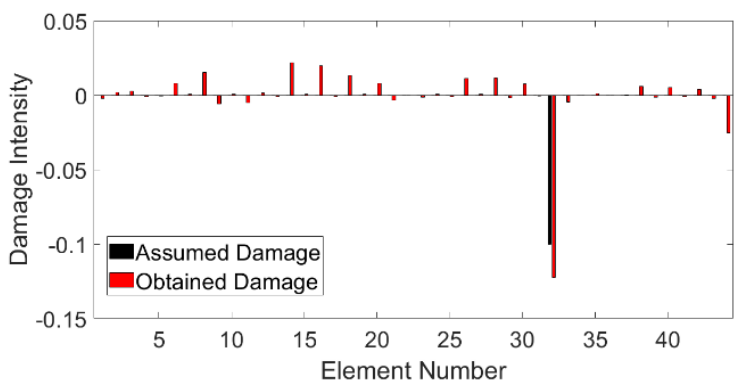

شكل rا شدت خرابى فرض شده و به دست آمده با استفاده از روش

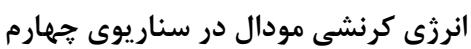

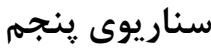

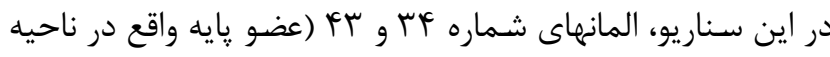

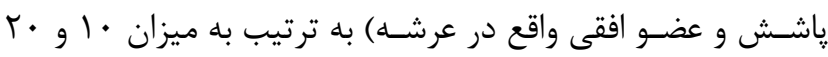

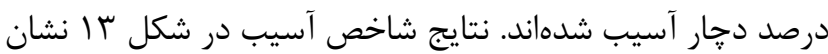

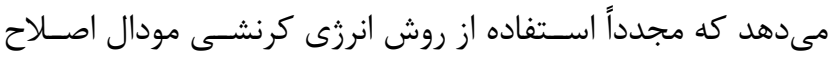
شــده منجر به بهبود نتايج مكانيابى آســيب شــده اســت. ميزان خطاى روش شاخص استابس در اين حالت برابر با NAC . ٪ و ميزان

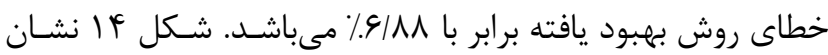
مىدهد كه روش انرزى كرنشى مودال دقت بالايى در تعيين شدت

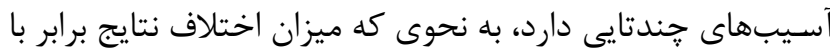

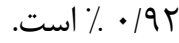

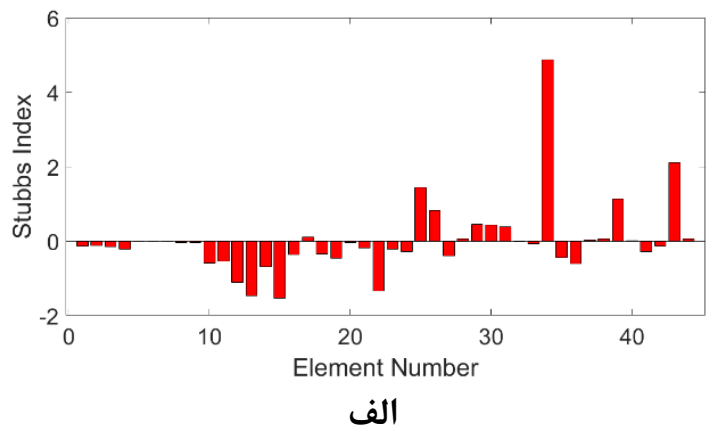


سيد رضا سمائى و همكاران/ إيش سلامت سازههاى دريايى به روش انرزى كرنشى مودال اصلاح شده (مطالعه موردى: زيرسازه شابلونى جهار پايه توربين بادى فراساحلى)

[5] S. W. Doebling, C. F. Farrar, M. B. Prime and D. W. Shevits, "Damage identification and health monitoring of structural and mechanical systems from chanes in their vibration characteristics: A literature review," Los Alamos National Laboratory, USA, 1996.

[6] D. Balageas, "Introduction to Structural Health Monitoring," in Structural Health Monitoring, Wiley, 2006, pp. 13-43.

[7] S. W. Doebling, C. R. Farrar, M. B. Prime and D. W. Shevitz, "A summary review of damage identification methods that examine changes in dynamic properties," Journal of Shock Vibration, vol. 30, pp. 91-105, 1995.

[8] P. Cawley and R. D. Adams, "The location of defects in structures from measurement of natural frequencies," The Journal of Strain Analysis for Engineering Design, vol. 14, pp. 49-57, 1979.

[9] F. Shahrivar and G. Bouwkamp, "Damage detection in offshore platforms using vibration information," Journal of Energy Resources Technology, vol. 108, pp. 97-106, 1986.

[10] S. R. Hansen and G. N. Vanderplaats, "Approximation method for configuration optimization of trusses," AIAAJ, vol. 28, pp. 161-168, 1990.

[11] S. Doebling, F. Hemez, M. Barlow, L. Peterson and C. Farhat, "Selection of experimental modal data sets for damage detection via model update," in 34th Structures, Structural Dynamics and Materials Conference, 1993.

[12] J. T. Kim and N. Stubbs, "Damage detection in offshore jacket structures from limited modal information," International Journal of Offshore and Polar Engineering, vol. 5, pp. 58-66, 1995.

[13] N. Stubbs, J. T. Kim and C. R. Farrar, "Field verification of a nondestructive damage localization and severity estimation algorithm," in Proceedings-SPIE the international society for optical engineering, 1995.

[14] N. Stubbs and J. T. Kim, "Damage localization in structures without baseline modal parameters," AIAA Journal, vol. 34, pp. 16441649, 1996.

[15] A. Salawu, "Detection of structural damage through changes in frequency: a review," Engineering Structures, vol. 19, pp. 718-723, 1997.

[16] C. R. Farrar and D. A. Jauregui, "Comparative study of damage identification algorithms applied to a brdige: II. Numerical study," Smart Materials and Structures, vol. 7, pp. 720-731, 1998.

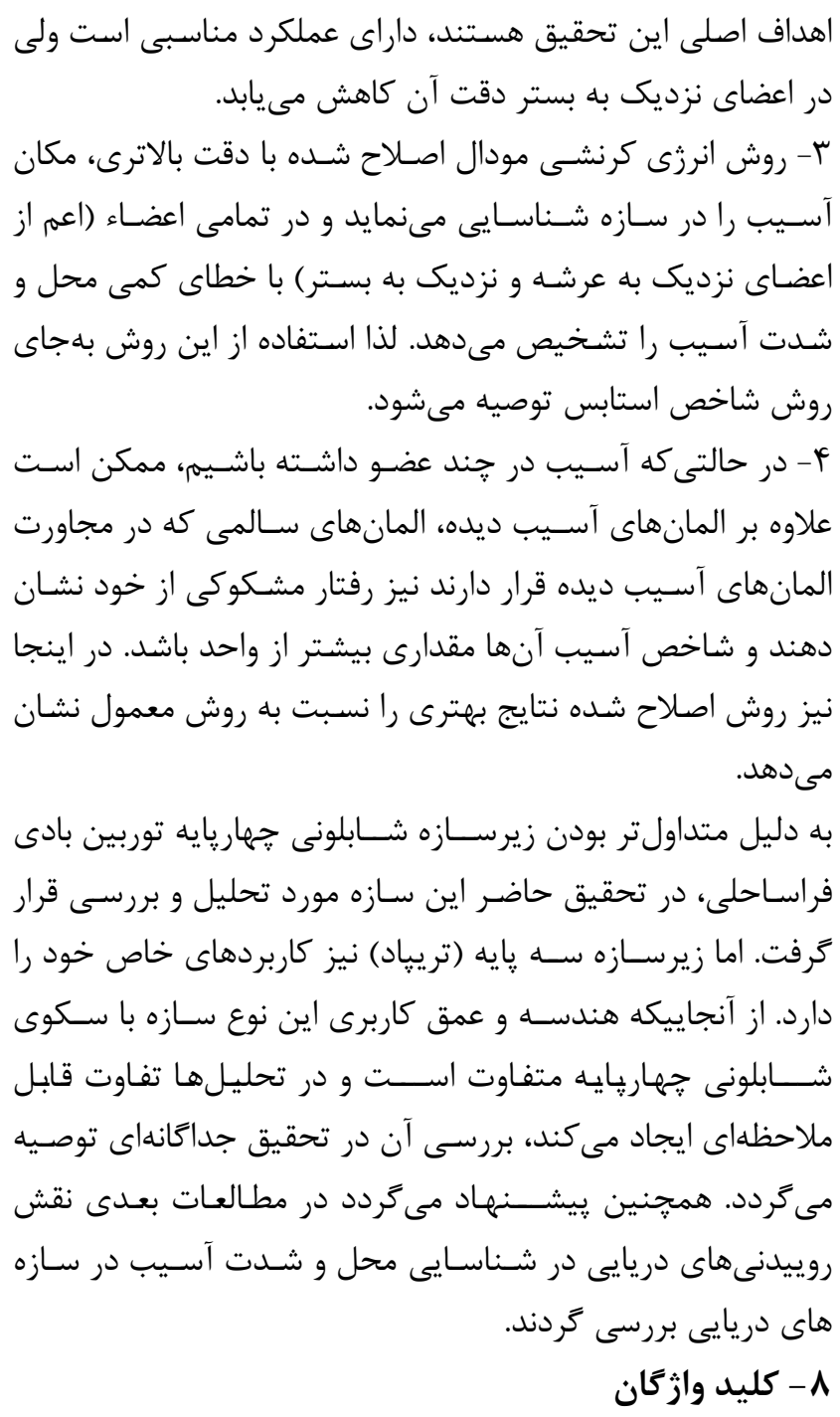

1- Compression Modal Strain Energy Change Ratio

2- Flexural Modal Strain Energy Change Ratio

$$
\text { 9- مراجع }
$$

[1] [Online]. Available: https://gwec.net/record-61-gw-of-new-offshore-wind-capacity-installedglobally-in-2019/.

[2] R. Rolfes, S. Zerbst, G. Haake, J. Reetz and J. P. Lynch, "Integral SHM-system for offshore wind turbines using smart wireless sensors," in 6th International Workshop on Structural Health Monitoring, Stanford, CA, 2007.

[3] C. P. Fritzen, "Vibration-Based Techniques for SHM," in Structural Health Monitoring, 2006, pp. 45-224.

[4] C. Bouty, S. Schafhirt, L. Ziegler and M. Muskulus, "Lifetime extension for large offshore wind farms: Is it enough to reassess fatigue for seleceted design positions?," Energy Procedia, vol. 137, pp. 523-530, 2017. 
[28] Y. Li, S. Wang, M. Zhang and C. Zheng, "An improved modal strain energy method for damage detection in offshore platform structures," Journal of Marine Science and Application, vol. 15, pp. 182-192, 2016.

[29] M. Martinez-Luengo, A. Kolios and L. Wang, "Structural health monitoring of offshore wind turbines: A review through the statistical pattern recognition paradigm," Renewable and Sustainable Energy Reviews, vol. 64, pp. 91105, 2016.

[30] C. U. Nguyen, T. C. Huynh and J. T. Kim, "Vibration-based damage detection in wind turbine towers using artificial neural networks," Structural Monitoring and Maintenance, vol. 5, pp. 507-519, 2018.

[31] W. Weijtjens, T. Verbelen, E. Capello and C. Devriendt, "Vibration based structural health monitoring of the substructures of five offshore wind turbines," Procedia Engineering, vol. 199, pp. 2294-2299, 2017.

[32] E. Lozano-Minguez, A. J. Kolios and F. P. Brennan, "Multi-criteria assessment of offshore wind turbine support structures," Renewable Energy, vol. 36, pp. 2831-2837, 2011.

[33] H. Bailey, K. L. Brookes and P. M. Thompson, "Assessing environmental impacts of offshore wind farms: lessons learned and recommendations for the future," Aquatic Biosystems, vol. 10, pp. 1-13, 2014.

[34] HSE, Offshore hydrocarbon release statistics and analysis 1992-2015, Bootle, UK: Health and Safety Executive, 2016.

[35] R. E. Melchers, "Probabilistic model for marine corrosion of steel for structural reliability assessment," Journal of Structural Engineering, vol. 129, pp. 1484-1493, 2003.

[36] J. C. Velaquez, J. M. Van Der Weide, E. Hernandez and H. H. Hernandez, "Statistical Modeling of Pitting Corrosion: Extrapolation of the maximum pit depth-growth," International Journal of Electrochemical Science, vol. 9, pp. 4129-4143, 2014.

[37] J. K. Paik and R. E. Melchers, Corrosion wastage in aged structures, 1st ed., Cambridge, UK: Woodhead Publishing, 2008.

[38] I. W. Chen, B. L. Wong, Y. H. Lin, S. W. Chau and H. H. Huang, "Design and analysis of jacket substractures for offshore wind turbines," Energies, vol. 9, pp. 1-24, 2016.
[17] J. T. Kim and N. Stubbs, "Improved damage identification method based on modal information," Journal of Sound and Vibration, vol. 252, pp. 223-238, 2002.

[18] Y. Y. Li, L. Cheng, L. H. Yam and W. O. Wong, "Identification of damage locations for plate-like structures using damage sensitive indices: strain modal approach," Computers \& Structures, vol. 80, pp. 1881-1894, 2002.

[19] H. Z. Yang, H. J. Li and S. Q. Wang, "Damage localization of offshore platforms under ambient excitation," China Ocean Engineering, vol. 17, pp. 495-504, 2003.

[20] M. Ge and E. M. Lui, "Structural damage identification using system dynamic properties," Computers \& Structures, vol. 83, pp. 21852196, 2005.

[21] S. Wang and H. Li, "Modal strain energy for damage detection of offshore jacket structures from partial modal information: Experimental validation," in Proceedings of the Sixteenth (2006) International Offshore and Polar Engineering Conference, San Francisco, California, USA, 2006.

[22] H. W. Shih, D. P. Thambiratnam and T. H. Chan, "Vibration based structural damage detection in flexural members using multicriteria approach," Journal of Sound and Vibration, vol. 323, pp. 645-661, 2009.

[23] H. Hu and C. Wu, "Development of scanning damage index for the damage detection of plate structures using modal strain energy method," Mechanical Systems and Signal Processing, vol. 23, pp. 274-287, 2009.

[24] S. M. Seyedpoor, "A two stage method for structural damage detection using a modal strain energy based index and particle swarm optimization," International Journal of NonLinear Mechanics, vol. 47, pp. 1-8, 2012.

[25] F. Liu, H. Li, W. Li and B. Wang, "Experimental study of improved modal strain energy method for damage localisation in jecket-type offshore wind turbines," Renewable Energy, vol. 72, pp. 174-181, 2014.

[26] S. M. Seyedpoor and O. Yazdanpanah, "An efficient indicator for structural damage localization using the change of strain energy based on static noisy data," Applied Mathematical Modeling, vol. 38, pp. 2661-2672, 2014.

[27] S. Wang, F. Liu and M. Zhang, "Modal strain energy based structural damage localization for offshore platform using simulated and measured data," Journal of Ocean University of China, vol. 13, pp. 397-406, 2014. 